THE RELATIONS AMONG OUTNESS, AUTHENTICITY, AND WELL-BEING FOR BISEXUAL ADULTS

\author{
A DISSERTATION IN \\ Counseling Psychology \\ Presented to the faculty of the University \\ of Missouri-Kansas City in partial fulfillment of \\ the requirements for the degree \\ DOCTOR OF PHILOSOPHY \\ By \\ JENNA MARIE BROWNFIELD
}

M.A., University of Denver, 2014

B.A., Rhodes College, 2012

Kansas City, Missouri

2018 
(C) 2018

JENNA MARIE BROWNFIELD

ALL RIGHTS RESERVED 


\title{
THE RELATIONS AMONG OUTNESS, AUTHENTICITY, AND WELL-BEING FOR BISEXUAL ADULTS
}

\author{
Jenna Marie Brownfield, Candidate for the Doctor of Philosophy Degree \\ University of Missouri-Kansas City, 2018
}

\begin{abstract}
Outness, a proximal minority stressor for sexual minority people, demonstrated inconsistent relationships with well-being. A possible explanation for these varied findings is that characteristics of one's sexual minority identity (e.g. identity prominence) moderate the relationship between proximal stressors and mental health outcomes. Newly studied, authenticity may be considered a characteristic of sexual minority identity and thereby influence the outness-well-being relationship. Additionally, a majority of research has examined the influence of minority stressors on the experiences of lesbians and gay men, and few studies have investigated the unique experiences of bisexual individuals. The present study examined the influence of outness (as a sexual minority and specifically as bisexual) and authenticity on bisexual adults' well-being, and whether authenticity moderated or mediated the relationship between outness and well-being. Four-hundred and fifty bisexual participants completed an online survey. Regression analyses revealed that bisexual disclosure positively predicted well-being when controlling for sexual minority disclosure, whereas bisexual concealment did not predict well-being when controlling for sexual minority concealment. Authenticity partially mediated the relationship between bisexual disclosure and well-being, and it mediated the relationship between bisexual concealment and well-being. Authenticity did not moderate either the relationship between bisexual


disclosure and well-being, nor the relationship between bisexual concealment and well-being.

Results further our understanding of bisexual individuals' mental health, particularly in regards to the influence of bisexual disclosure and concealment. 


\section{APPROVAL PAGE}

The faculty listed below, appointed by the Dean of the School of Education have examined a dissertation titled "The Relations Among Outness, Authenticity, and Well Being for Bisexual Adults," presented by Jenna M. Brownfield, candidate for the Doctor of Philosophy, and certify that in their opinion it is worthy of acceptance.

\section{Supervisory Committee}

Chris Brown, Ph.D., Committee Chair

Division of Counseling and Educational Psychology

Carolyn Barber, Ph.D.

Division of Counseling and Educational Psychology

Kim Langrehr, Ph.D.

Division of Counseling and Educational Psychology

Nancy Murdock, Ph.D.

Division of Counseling and Educational Psychology

Laurel Watson, Ph.D.

Division of Counseling and Educational Psychology 


\section{CONTENTS}

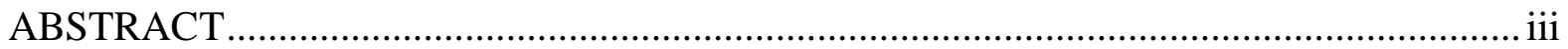

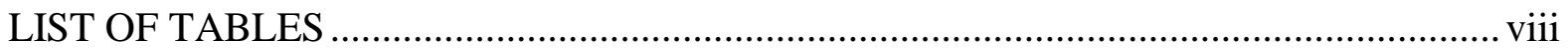

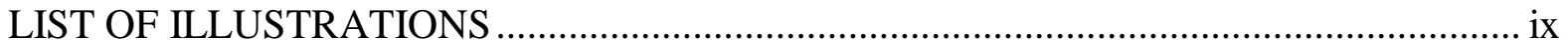

ACKNOWLEDGMENTS ....................................................................................

Chapter

1. INTRODUCTION AND REVIEW OF THE LITERATURE ...................................... 1

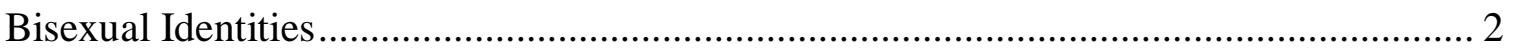

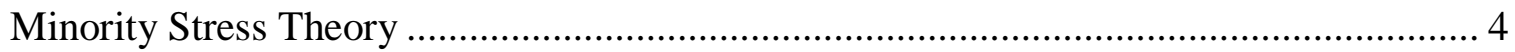

Minority Stress for Lesbians and Gay Men ......................................................... 7

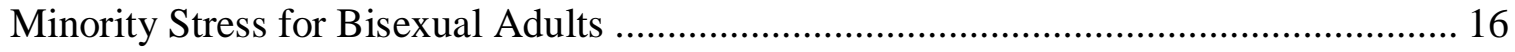

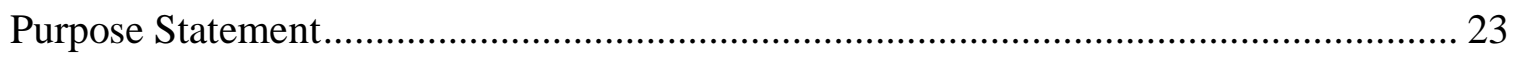

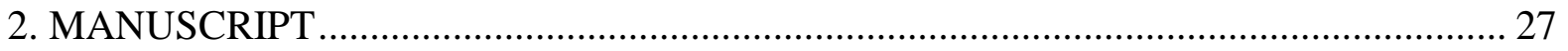

Introduction and Review of the Literature ........................................ 27

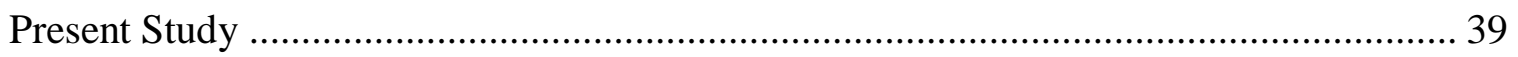

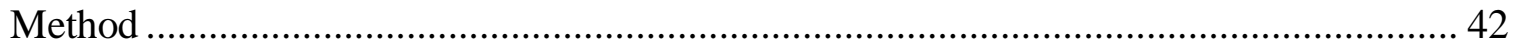

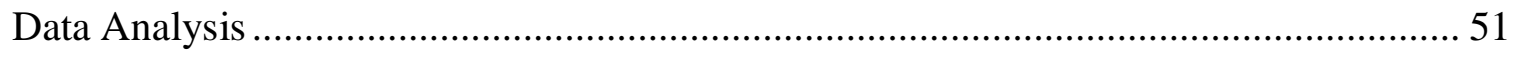

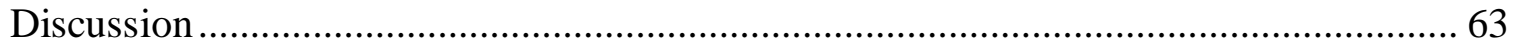

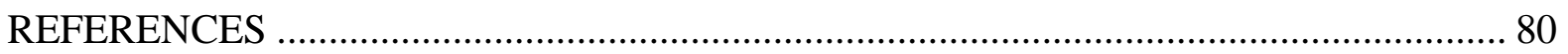

\section{APPENDICES}

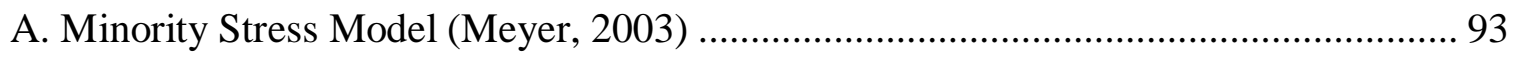

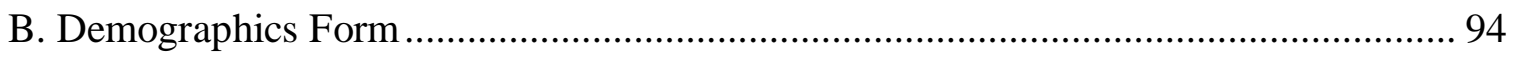

C. Nebraska Outness Scale (Meidlinger \& Hope, 2014) ............................................. 97 


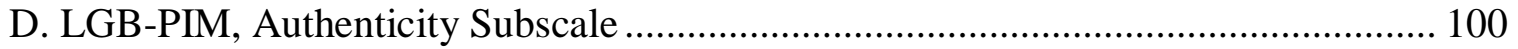

E. Psychological Well-Being Scale .......................................................................... 101

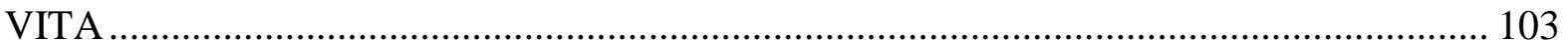




\section{LIST OF TABLES}

Table $\quad$ Page

1. Correlations, Reliability Coefficients, and Descriptives ..........................90

2. Hierarchical Multiple Regression Analysis Predicting PWBS $\ldots \ldots \ldots \ldots \ldots \ldots \ldots \ldots \ldots \ldots . \ldots 1$ 


\section{LIST OF ILLUSTRATIONS}

Figure

Page

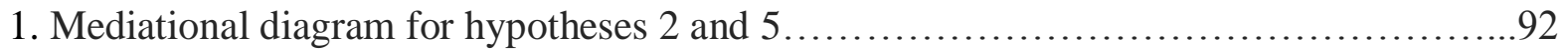




\section{ACKNOWLEDGMENTS}

This dissertation would not have been possible without the support and guidance from multiple people. First, I would like thank my advisor, Dr. Chris Brown. Her mentorship and constant enthusiasm throughout my doctoral career has instilled in me the belief that research can be meaningful, personal, and do-able! I also appreciate the members of my dissertation committee for their input throughout this process: Dr. Carolyn Barber, Dr. Kim Langrehr, Dr. Nancy Murdock, and Dr. Laurel Watson. In addition, I would like to thank Dr. Pat Garriott, Dr. Lindsey Brooks, and Dr. Kevin Delucio. Their mentorship over the past few years have been incredible valuable to me and without them, I would not be where I am today.

On a more personal note, I would like to thank my parents (Richard and Margo Brownfield), my sister (Dayna Brownfield), and my grandparents (Novella and David Brownfield). They have all been a source of encouragement and love from the very beginning of my formal education. I cannot thank them enough for all the ways they helped me reach this achievement. Thank you to my partner (Evan Stanforth) for always reminding me that my ambitions are not necessarily mountains to be climbed, but are evidence that I can and will be a good psychologist. I also want to say thank you to my friend and cohort member, Amanda McLarty.

Thank you to all the bisexual people (within and outside the psychology field) that have come before me. Your labor in fostering bisexual visibility made this dissertation possible. This dissertation is dedicated to you and is part of your legacy. I also want to thank the numerous bisexual individuals and researchers who provided input on the dissertation, reviewed measures, and participated in the study itself! Finally, thank you to all the amazing 
bi people in my life. Having community with you all has provided me so many wonderful memories. 


\section{CHAPTER 1}

\section{INTRODUCTION AND REVIEW OF THE LITERATURE}

A central tenet in counseling psychology is to work with strengths and focus on positive functioning (Gelso, Nutt Williams, \& Fretz, 2014). Popularization of the term positive psychology by Martin Seligman furthered the amount of attention given to positive functioning (Gelso et al., 2014). Seligman and Csikszentmihalyi (2000) expounded upon this term when they introduced a three-pillar, strengths-perspective framework, stating that positive psychology includes three domains. The first pillar consisted of positive subjective experiences such as positive emotions, the second pillar contained positive individual traits such as various character strengths and virtues (e.g. authenticity), and the third pillar captured positive institutions and communities that foster the first two pillars. By examining research questions housed in one or more of these pillars, counseling psychologists can contribute to positive psychology research.

Similar to counseling psychology research broadly, a majority of LGBT-focused research is conceptualized from a deficit model (Vaughan et al., 2014). This occurrence is particularly evident in the frequency of distress and dysfunction serving as outcome variables in LGBT research. In effort to foster a more balanced narrative of LGBT experiences, Vaughan et al. (2014) made a call for more positive psychology LGBT research studies and offered a content analysis of existing studies. Specifically, Vaughan et al. (2014) pointed to Seligman and Csikszentmihalyi’s (2000) three-pillar, strengths-perspective model as a framework for conducting LGBT positive psychology research. They suggested that LGBT researchers investigate factors encompassed in one or more of the three pillars as the 
implications of such research may assist in depathologizing and affirming LGBT identities. Vaughan et al. (2014) also noted there has been minimal attention directed at investigating the specific experiences of bisexual, queer, transgender, and LGBT people of color compared to lesbian and gay individuals within LGBT positive psychology studies. This gap in the literature points to a need for the study of positive psychology factors within specific LGBT subgroups, such as bisexual individuals. It is important to keep in mind the unique stressors faced by bisexual individuals, such as the discrimination encountered by both the heterosexual/straight community and the lesbian/gay community and societal messages of bisexuality being a phase or inauthentic identity (Brewster \& Moradi, 2010). Thus, it seems imperative to examine the ways in which bisexual individuals are thriving despite this societal context.

\section{Bisexual Identities}

Although often included in the LGBTQ (lesbian, gay, bisexual, transgender, queer/questioning) acronym, bisexual individuals may feel distinct from the monosexual LG community. The bisexual movement in the 1970s through 1990s tended to define nonmonosexual identities as being attracted to both men and women (Eisner, 2013). However, today there seems to be a more inclusive conceptualization of bisexuality. In order to acknowledge nonbinary gender individuals, bisexuality is now commonly defined as "attraction to people of more than one sex or gender; attraction to people of genders similar to our own, and to people of genders different from our own; or attraction to people of multiple genders" (Eisner, 2013, p. 20). A similar definition of bisexuality referring to people 
with attractions to multiple genders has been offered from BiNet USA (2015). Robyn Ochs, a bisexual activist, also provided an almost identical definition when she stated:

I call myself bisexual because I acknowledge in myself the potential to be attracted - romantically and/or sexually - to people of more than one sex and/or gender, not necessarily at the same time, not necessarily in the same way, and not necessarily to the same degree.

Additionally, Flanders, LeBreton, Robinson, Bian, and Caravaca-Morera (2017) recently surveyed 60 bisexual and pansexual young adults regarding their definitions of bisexuality. Participants defined bisexuality in similar ways, describing bisexuality as romantic or sexual attraction to two or more genders. These non-binary inclusive definitions of bisexuality will serve as the understanding of bisexuality for the present study.

The identity label of bisexual is utilized as a "Community Identity Label," that can encompass a multitude of non-monosexual identity labels such as pansexual and queer (BiNetUSA, 2015, p. 3). In addition to the community label of bisexual, some bisexual people use "Personal Identity Labels" in order to better capture their sexuality (BiNetUSA, 2015, p. 3; Dyar, Feinstein, \& London, 2015). Someone may identify broadly with the community label of bisexual, but more specifically define themselves as pansexual or queer. Keeping this in mind, researchers studying bisexual individuals have begun offering bisexual participants space to report additional identity labels if they believe the term 'bisexual' does not fully capture their identity (Brownfield, Brown, Jeevanba, \& VanMattson, 2018; Watson, Velez, Brownfield \& Flores, 2016). 
A recent report assembled by the Movement Advancement Project (MAP) detailed that $5.5 \%$ of women and $2 \%$ of men in the United States identify as bisexual, and of people in the United States who identify as either L, G, or B, 52\% of them identify as bisexual (2016). Despite the abundance of bisexual individuals (sometimes referred to as the “invisible majority"), in the United States LGB population, their experience and health needs are rarely studied separately from LG individuals (MAP, 2016). This lack of attention to research on bi-specific samples not only renders the unique experiences and needs of bisexual individuals being rendered invisible, but also paints an inaccurate portrayal of LG individuals' experiences and needs. The absence of bi-specific research is so pronounced that a review of sexuality scholarship in the social sciences from 1970-2015 showed the topic of biphobia receiving less attention in publications compared to homophobia (Monro, Hines, \& Osborne, 2017). This lack of attention may be indicative of biphobia manifesting within the social science community (Monro et al., 2017). It is also noteworthy to remember the social science history of using behaviors to define sexuality in a binary sense, which resulted in many participants who indicated same-sex behaviors in research being categorized as "homosexual," thereby erasing experiences of bisexuality (Monro et al., 2017). Thus, social science research needs to expand sexuality scholarship by examining the specific experiences of bisexual individuals while using the more modern definitions of bisexuality.

\section{Minority Stress Theory}

Minority stress theory arose as an expansion of more general stress theories to the experiences of LGB individuals (Meyer, 2003). Meyer (2003) saw many stress theorists as being influential to understanding the minority stress of lesbian, gay, and bisexual (LGB) 
individuals. For instance, Lazarus and Folkman (1984) conceptualized that social stressors occur when one has incongruence between one's experience of themselves and their experience of society, and Selye (1982) viewed stress as manifesting when a person is not in harmony with their environment. Both of these theories were influential in understanding minority stress experiences. Meyer (2003) proposed that minority stress occurs in addition to general stressors and is chronic, and stems from social processes, institutions, and structures. Due to his theoretical tenet that minority stressors are an addition to general stressors, he believed this additional stress could account for the higher incidence of mental health concerns among LGBT people compared to heterosexual people.

Further inspired by Lazarus and Folkman's (1984) work on stress, Meyer (2003) proposed that minority stressors existed along a spectrum of distal-proximal stressors; with distal stressors being objective, environmental experiences and proximal stressors being the individual subjective perceptions stemming from distal stressors. More specifically, distal stressors for LGB individuals may include experiences of prejudice, discrimination, and antiLGB violence, whereas proximal stressors for LGB individuals may include expectations of rejection, concealing of LGB identity, and internalized stigma of LGB identity (Meyer, 2003). It is hypothesized that greater degrees of these stressors predict greater negative mental health outcomes and less positive mental health outcomes (e.g. prevalence of psychological disorders, depression symptoms, substance use, psychological well-being, etc.: Meyer, 2003).

However, various factors play a role in the relationship between minority stressors and mental health outcomes. Meyer (2003) noted that individual's LGB-related coping and 
social support could lessen the impact of minority stressors on their mental health outcomes. Also, the characteristics of an individual's minority identity (such as the saliency, valence, integration of their LGB identity) could modify the relationship between proximal stressors and mental health outcomes such that the relationship is strengthened or weakened (Meyer, 2003). For example, proximal stressors (e.g. concealing one's sexual orientation) resulted in worse mental health outcomes for someone with a high level of LGB identity saliency compared to someone with a low level of saliency (Thoits, 1999 as cited in Meyer, 2003). See Appendix A for Meyer's (2003) minority stress model.

After studying the effects of minority stress on gay men, Meyer (1995) stated a need for additional studies in order to illuminate the impact of minority stress for other minority groups. More specifically, he explained the problems inherent in generalizing research findings on minority stressors for gay men to lesbians (Meyer, 1995). The duality of lesbians facing multiple stigmatizing identities (e.g. being gay and being a woman), calls for specific study of how this population experiences minority stressors (Meyer, 1995). Thus, there is a need to continue examining ways minority stressors affect different groups of marginalized people. This research could include examining the way minority stressors affect bisexual individuals' health given that bisexual people hold multiple stigmatized identities (i.e., as nonheterosexual and specifically as bisexual). Meyer (1995) also emphasized the need to examine factors that may explain in-group variance of minority stressors on marginalized people's health (e.g. how coping influences the relationship between experiencing minority stressors and distress). Meyer appealed for further investigation of factors that allow marginalized people to "thrive in the face of societal oppression" (1995, p. 52). This call for 
further research highlights the need to not only study the direct effect of minority stressors on marginalized people's health, but also to include possible moderating and mediating variables in future studies and to do so within a positive psychology lens.

\section{Minority Stress for Lesbians and Gay Men}

\section{Role of Outness, Disclosure, and Concealment}

Outness is often measured as either the degree to which one discloses their sexual orientation or one's degree of concealment. Meidlinger and Hope (2014) explained the distinctions between disclosure and concealment in that disclosure refers to actively sharing one's sexual orientation (verbally or non-verbally), and concealment refers to actively avoiding one's sexual orientation being shared.

Furthermore, Meidlinger and Hope (2014) identified outness as a construct consisting of both these factors (disclosure and concealment). Nonetheless, researchers have repeatedly confused the distinctions in these constructs, oftentimes measuring outness only within the context of either disclosure or concealment, not both (Brewster, Moradi, DeBlaere, \& Velez, 2013; Watson et al., 2016). One of the most commonly utilized measures of outness, the Outness Inventory (OI; Mohr \& Fassinger, 2000) conceptualized greater outness as having greater verbal disclosure(s), placed non-verbal disclosure(s) as a stepping-stone to verbal disclosure(s), and did not measure any form of concealment. Whereas verbal disclosure is the degree to which one's sexual orientation is known and talked about with others, non-verbal disclosure would be the degree to which others know about one's sexual orientation but do not discuss it (Mohr \& Fassinger, 2000; Villicana, Delucio, \& Biernat, 2016). 
Studies specifically examining LGB people's levels of disclosure in relation to psychological outcomes show mixed results. Some studies reveal disclosure being related to negative experiences such as greater discrimination (Ragins \& Cornwell, 2001), other studies report disclosure predicting positive experiences such as greater well-being (Riggle, Rostosky, Black, \& Rosenkrantz, 2017; Velez \& Moradi, 2016), and some studies do not find disclosure to be a significant predictor of mental health outcomes (Jackson \& Mohr, 2016). Thus, it seems there are advantages and disadvantages to disclosure. Jackson and Mohr's (2016) study reported degree of disclosure (as measured by the OI) did not significantly predict psychological outcomes (e.g. depression, life satisfaction: Jackson \& Mohr, 2016). However, a study conducted by Velez and Moradi (2016) also used the OI and reported it significantly negatively predicted participants' psychological distress and it significantly positively predicted participants' psychological well-being.

In addition, research comparing the relationship between verbal disclosure (using the OI) and well-being for gay White men and gay Latino men showed differences in this relationship, suggesting the relationship between outness and mental health outcomes may vary by race and ethnicity (Villicana et al., 2016). Interaction effects between ethnicity and verbal disclosure on well-being revealed no relationship between verbal outness and wellbeing for gay Latino men, but there was a positive relationship between these variables for gay White men such that greater verbal disclosure was related to greater psychological wellness (Villicana et al., 2016). More specifically, the authors note how at levels of low verbal disclosure, gay Latino men reported greater well-being than gay White men. These findings capture how outness, when more narrowly conceptualized as verbal dislosure(s), 
was not a predictor of well-being for all gay men (Villicana et al., 2016). In addition, these findings reveal that being verbally out to others is not a necessity that all gay individuals must enact in order to achieve well-being, and these findings dispel the White gay narrative often perpetuated onto all gay men of greater verbal outness being directly beneficial to wellbeing. Thus, it is imperative that outness be examined with an intersectional lens.

The potential applicability of these cultural differences for the bisexual community seem important given that people of color, compared to White individuals, are more likely to identify as bisexual (Movement Advancement Project [MAP], 2016), and 21\% of bisexual men identify as Hispanic (Herek, Norton, Allen, \& Sims, 2010). As such, the selection of outness measures that abstain from organizing different styles of disclosure (verbal vs. nonverbal) along a hierarchy would be an important consideration when conducting research on bisexual participants. When using the OI, one's degree of verbal disclosure receives a higher score than one's degree of non-verbal disclosure. In other words, when using the OI, participants who engage in any level of verbal disclosure are classified as having greater outness than those who only use non-verbal disclosure tactics. Measurement considerations aside, Villicana et al.'s (2016) findings seem valuable to bisexual research given the racial/ethnic diversity in the bisexual population and a need to better understand how and when disclosure predicts well-being from an intersectional lens. Thus, examining potential moderators in the relationship between disclosure and well-being would allow a more nuanced understanding of this relationship, instead of assuming a direct relationship between disclosure and well-being for all bisexual individuals. 
In regards to the role of concealment within a minority stress model, even though concealing one's LGB identity may serve as a coping strategy against stigma, the effort to conceal can also weigh heavily on an LGB individual and thus lead to increased stress (Smart \& Wegner, 2000). A review of the literature captures the negative physiological effects of concealing one's sexual orientation. Specifically, concealment behavior was associated with long-term health consequences such as dysregulated immune function and increased occurrence of infectious diseases (Lick, Durso, \& Johnson, 2013). Jackson and Mohr (2016) also found a positive relationship between concealment behavior and depression among a sample of 353 LGB college students; their findings further revealed a negative relationship between concealment behavior and life satisfaction. Similarly, concealment behavior negatively predicted psychological well-being in a sample of 373 lesbian and bisexual women (Selvidge, Matthews, \& Bridges, 2008). The impact of concealment has even been studied in heterosexual participants. Critcher and Ferguson (2014) conducted four experimental studies that revealed decreases in cognitive performance and physical stamina when heterosexual participants were instructed to conceal their sexual orientation (e.g. do not signify the gender of people you date) during a short 10-minute interview. These findings together demonstrate the immediate and long-term effects of sexual orientation concealment.

Riggle et al. (2017) examined the unique influences of both disclosure and concealment on well-being. Results showed that among LGB individuals there was a negative association between concealment and well-being (i.e. psychological wellness and positive functioning) and a positive association between disclosure and well-being (Riggle et al., 2017). Studies continue to demonstrate the distinction between disclosure and 
concealment as separate constructs (Jackson \& Mohr, 2016; Meidlinger \& Hope, 2014). Meidlinger and Hope (2014) developed a new measure (Nebraska Outness Scale; NOS) with a sample of 192 LGB participants in order to examine if these separate aspects of outness, disclosure and concealment, could be conceptually combined as a single-factor representation of outness. According to Meidlinger and Hope, the NOS better reflects the distinctions between disclosure and concealment as related but separate processes that can be combined to understand one's degree of outness.

Previous studies reported associations between outness and well-being. In their attempt to understand predictors and outcomes of outness, Morris, Waldo, and Rothblum (2001) found that greater outness related to less psychological distress in a sample of 2,401 lesbian and bisexual women. In another study examining outness as a predictor of psychological outcomes in a sample of 192 sexual minority participants, outness as measured by the NOS positively predicted quality of life (Meidlinger \& Hope, 2014). However, research has demonstrated that outness is not always predictive of LGB people's mental health.When studying the influence of self-esteem, outness, internalised (sic) homophobia, and mobile dating application use in a sample of 698 gay and bisexual men, outness (as measured by the NOS) did not significantly predict general mental health (O'Conner, 2016). Keeping in mind the inconsistent findings in the relationship between outness (specifically as a composite of disclosure and concealment) and mental health outcomes, it appears other factors may be mediating or moderating this relationship.

\section{Role of Authenticity}


Another factor to consider in discussions of outness, disclosure, and concealment is authenticity, which refers to the intrapersonal experience of being true to one's sense of self and one's values (Riggle et al., 2017). Authenticity surfaced as a frequent theme in a foundational investigation on positive psychology for lesbian and gay individuals (Riggle, Whitman, Olson, Rostosky, \& Strong, 2008). In this qualitative study, Riggle et al. (2008) asked participants to report the positive aspects of having a gay or lesbian identity. Their findings from 203 gay men and 350 lesbians revealed that authenticity and honesty with self and others was the most common theme. The frequency of this theme captured the salience of authenticity for LG individuals. The authenticity achieved by LG individuals also appeared to positively influence their well-being. A lesbian participant noted, "I am living authentically, which feeds my confidence, my joy and happiness, my relationship with God, my improved health" (Riggle et al., 2008, p. 213), thereby suggesting that authenticity may be associated with good mental health for LG individuals.

Continued efforts to study the role of authenticity for LGB individuals led Riggle, Mohr, Rostosky, Fingerhut, and Balsam (2014) to develop a multifactor positive identity measure (referred to as the LGB-Positive Identity Measure [LGB-PIM]). A five-item subscale capturing LGB people's experiences of authenticity arose in the scale development results for a sample of 264 LGB individuals. Examples of these items included "I am honest with myself about my LGBT identity" and "I feel I can be honest and share my LGBT identity with others" (Riggle et al., 2014). This newly developed LGB authenticity subscale positively correlated with a second sample of 272 LGB participants' satisfaction with life (Riggle et al., 2014), furthering evidence of an association between authenticity and positive 
mental health outcomes for LGB people. In their discussion, Riggle et al. (2014) emphasized that the inconsistent findings of outness as a predictor to well-being demonstrate a more complex picture for this relationship, and authenticity may help us better conceptualize the influence of outness on well-being.

Riggle et al. (2017) further explained that authenticity may relate to one's decisions about disclosing or concealing their sexual orientation. For example, one may work towards greater disclosure or less concealment as a way to obtain greater authenticity (Szymanski, Mikorski, \& Carretta, 2017). In a more recent study using the LGB-PIM authenticity subscale, Riggle et al. (2017) found that authenticity uniquely positively predicted psychological well-being for a sample of LGB individuals when controlling for outness (defined as disclosure), concealment, and education. This significant finding suggests authenticity plays a unique role in LGB people's experiences of well-being.

In order to understand experiences of minority stress and resilience for sexual minority individuals, Levitt et al. (2016) conducted a qualitative study using a grounded theory approach. Their sample of sexual minority adults (6 identified as gay, 7 identified as lesbian, and 3 identified as bisexual) reported that their experiences with minority stressors led them to feel conflicted between being authentic about their LGB identity and risking selfdetermination (i.e., having autonomy, abilities to accomplish goals, and/or a sense of belonging), or being inauthentic and maintaining self-determination. Levitt et al. (2016) noted that achieving authenticity via the integration of various identities seemed to positively influence LGB people's mental health, whereas having to live inauthentically as a response to minority stressors had a negative impact on the individual's well-being (Levitt et al., 
2016). They further concluded that their findings call for additional study of authenticity within the context of minority stress.

Birichi (2015) also believed authenticity may be a factor that explains a sexual minority person's ability to thrive in the face of minority stressors. He explained the importance of studying the role of authenticity in minority stress for sexual minority individuals when he stated, "Authenticity may be particularly salient for such individuals because they face a choice between having to hide parts of themselves that may not be generally accepted in society" (Birichi, 2015 p. 7). To examine this possibility, he analyzed the relationship between minority stressors (experiences of discrimination, expectations of rejection, internalized homophobia, and concealment of orientation), authenticity, eudaimonic well-being (i.e., flourishing, purpose in life, personal growth, positive relationships with others, etc.) and hedonic well-being (i.e., positive affect, life satisfaction, lack of negative affect) in a sample of 226 gay men. Results demonstrated a significant, negative relationship between participants' degree of concealment (measured by reversescoring the OI; Mohr \& Fassinger, 2000) and their authenticity. Results also showed significant positive relationships between authenticity and eudemonic well-being, and between authenticity and hedonic well-being. Given these findings, Birichi (2015) then tested the potential mediating effects of authenticity between concealment and eudemonic wellbeing, and between concealment and hedonic well-being. His findings revealed that authenticity partially mediated the relationship between concealment and eudemonic wellbeing, and it fully mediated the relationship between concealment and hedonic well-being. More specifically, concealment was related to less authenticity, which was then related to 
less eudemonic and hedonic well-being. These findings elucidate the significance of possessing authenticity for sexual minority individuals given the context of having concealable identities, and Birichi (2015) encouraged future studies to investigate these relationships for different sexual orientations and gender identities such as with lesbian, bisexual, and transgender individuals.

Villicana et al. (2016) provided findings on the role of intrinsic self-expression (stated as being akin to authenticity) in the relationship between verbal disclosure and subjective well-being. More specifically, they investigated the potential mediating influence of intrinsic self-expression between verbal disclosure (measured using the OI) and subjective well-being, and how this mediating relationship varied for gay White men $(n=57)$ compared to gay Latino men $(n=59)$. Their findings reflected that although a significant mediation was found for gay White men, no such mediation was evident for gay Latino men. Nonetheless, the path from intrinsic self-expression to subjective well-being was significant for both gay White men and gay Latino men. Their findings demonstrated that authenticity, as measured by intrinsic self-expression, played a significant role in gay men's well-being across these two racial backgrounds. However, given that the path from verbal disclosure to authenticity was not significant across both samples of gay men, the findings showed that verbal disclosure cannot predict authenticity for all gay men. Whereas gay White men may achieve authenticity via greater verbal disclosure, gay Latino men likely have different strategies that allow them to achieve authenticity. It appears that verbal disclosure increases one's sense of authenticity for gay White men, but does not have the same effect for gay Latino men. Regardless of how authenticity is achieved, both groups of gay men reported greater well- 
being when having higher authenticity. Furthermore, these results highlight how using a limited definition of outness, such as emphasizing verbal disclosures over non-verbal ones, resulted in different mediation results for the path from verbal disclosure to intrinsic selfexpression to subjective well-being across these two racial backgrounds. Keeping these findings in mind, it seems pertinent to further examine the role of authenticity in the link between different types of outness (e.g. disclosure and concealment) and well-being, as either a mediator or possibly a moderator, instead of assuming a direct relationship between these variables for all LGB individuals.

At this time, few studies exist that include the variable of authenticity in models of outness and well-being (Riggle et al., 2017). Given that authenticity is defined as an intrapersonal process, perhaps authenticity can be considered a characteristic of minority identity, and therefore fit within the minority stress model (see Appendix A). If this is the case, it seems that authenticity would serve as a moderator in the relationship between a proximal stressor (such as outness) and psychological outcomes (such as well-being).

\section{Minority Stress for Bisexual Adults}

When scribing a model for minority stress, Meyer (2003) emphasized that bisexual individuals likely experience minority stressors differently than gay and lesbian individuals. His reasoning for this is grounded in evidence from a large community survey assessing the mental health of LGB individuals. Results of the survey showed bisexual individuals ( $n=71)$ reported a greater number of stressors and mental health concerns than gay and lesbian individuals ( $n=78$; Jorm, Korten, Rodgers, Jacomb, \& Christensen, 2002). Miller, André, Ebin and Bessonova (2007), as part of The National Gay and Lesbian Task Force, recently 
issued a report on bisexual health. When reporting on why it is important to focus on bisexual health concerns, the task force noted that bisexual individuals reported poorer mental health than gay and lesbian individuals, and they explained that caution should be given to grouping together monosexual individuals (gay and lesbian) with bisexual individuals in mental health research. Of note, the article to which the National Gay and Lesbian Task Force is referring (Jorm et al., 2002) used the term "homosexual" when referring to lesbians and gay men. This term is used below when included as quoted text in light of the terms 'lesbian and gay men' being more accurate and preferable to the negatively associated and pathologizing term 'homosexual.' In their study, Jorm et al. (2002) concluded that bisexual individuals reported the worst mental health outcomes, with "homosexual" participants having slightly better mental health and heterosexual participants reporting the best mental health of the three groups. Upon seeing this distinction, Jorm et al., (2002) emphasized that previous findings of mental health for "homosexuals" may be overstated due to having aggregated samples of bisexuals and "homosexuals." Together these findings highlight the importance of examining the impact of minority stressors for bisexual individuals and gay/lesbian individuals separately. Enacting such a practice will allow researchers to more clearly understand the unique mental health experiences of both bisexual and gay/lesbian individuals. Several theories may prove useful when studying the specific mental health disparities of bisexual individuals, such as employing minority stress theory (Persson \& Pfaus, 2015).

It seems likely that the increased mental health concerns reported by bisexual adults could be a result of bisexual individuals not only navigating stressors related to one's same- 
gender attraction, but also related to one's ability to feel attraction to multiple genders. In other words, bisexual individuals are faced with stressors stemming from homophobia/heterosexism and biphobia/monosexism. To illuminate this experience, consider that a bisexual person may encounter stress in response to others' negative attitudes regarding someone having same-sex attractions and they may feel stress in response to others' beliefs that bisexuality is not real or valid. However, a gay or lesbian person may encounter similar stress from others' negative attitudes regarding same-sex attractions, but they would not experience stress from the latter. Encountering discrimination from both the heterosexual/straight community and the LG community surfaces as another unique minority stressor for bisexual individuals (Brewster \& Moradi, 2010; Mitchell, Davis, \& Galupo, 2015; Roberts, Horne, \& Hoyt, 2015). The impact of these additional bisexual-specific stressors is reflected in the higher rates of mental health concerns for bisexual adults compared to LG adults (Molina et al., 2015).

Research using minority stress theory reflects the distinct experiences of minority stress for bisexual individuals. In efforts to support further study of minority stress for bisexual individuals, Paul, Smith, Mohr, and Ross (2014) developed a multidimensional measure, titled the Bisexual Identity Inventory (BII) capturing various aspects of bisexual identity (e.g. anticipated binegativity, internalized binegativity, etc.). The creation of this instrument provided a way to quantitatively assess for bisexual-specific minority stressors and thereby better understand the unique minority stressors of bisexual individuals. Molina et al. (2015) demonstrated the applicability of minority stress theory to bisexual women in regards to bisexual-specific minority stressors. Results from a sample of 470 bisexual women 
revealed that bi-specific minority stressors, such as experienced bi-negativity and internalized bi-negativity, positively predicted depression symptoms. These findings capture the benefit of studying bisexual individual's mental health within a minority stress model that is bi-specific.

\section{Role of Outness, Disclosure, and Concealment}

A specific stressor that bisexual individuals navigate is their level of outness (i.e. experiences of disclosure and/or concealment). Several studies have made efforts to better understand the minority stress experiences of bisexual individuals' in regards to their levels of outness (Brewster et al., 2013; Molina et al., 2015; Roberts et al., 2015). These studies offer a foundational conceptualization of outness as a minority stressor for bisexual individuals. Of note though is that most of these studies utilize the OI to measure outness, which inquires only about disclosure and not about concealment.

For instance, when studying the role of minority stressors on mental health in a sample of 411 bisexual adults Brewster et al. (2013) found a significant positive correlation between one's outness as bisexual (as measured by the OI) and their psychological wellbeing. Their results also revealed outness as bisexual served as a partial mediator between antibisexual prejudice (a distal stressor) and well-being (Brewster et al., 2013). This mediation demonstrated that greater antibisexual prejudice predicted greater outness, which then predicted greater well-being (Brewster et al., 2013). Thus, outness as bisexual appears to be related to both benefits (such as greater well-being) and risks (such as greater prejudice). In another study examining the influence of outness within a minority stress framework for a sample of 353 bisexual women, outness (as measured by the OI) showed a negative 
association with disordered eating, which approached, but did not quite reach, significance $(p=.05$; Watson et al., 2016).

There is research that has successfully teased apart the conceptual differences between outness, disclosure, and concealment for bisexual individuals. Schrimshaw, Siegal, Downing, and Parsons (2013) investigated relationships between disclosure and concealment (as separate variables) on mental health outcomes in a sample of 203 non-gay-identified, bisexually-behaving men. Results revealed that disclosure (as assessed with a measure different from the OI) did not significantly predict any of the three psychological outcome variables measured (depression symptoms, anxiety symptoms, positive affect). Schrimshaw et al.'s (2013) findings demonstrate that even when measuring disclosure with measures other than the OI, the direct relationship between disclosure and psychological outcomes is not always a significant relationship.

These research findings offer mixed results regarding the relationship between outness (using the OI or other disclosure-only measures) and psychological outcomes for bisexual individuals. Some studies revealed outness to predict positive psychological outcomes (Brewster et al., 2013), and some studies showed no significant relationship between outness and psychological outcomes (such as depression symptoms, Molina et al., 2015; on depression symptoms, anxiety symptoms, and positive affect: Schrimshaw et al., 2013; disordered eating symptoms, Watson et al., 2016). These mixed findings warrant researchers to continue examining the impact of outness for bisexual individuals. In particular, these findings highlight the need to include more expansive definitions of outness 
(other than simply measuring disclosure) and/or the role of additional variables in the relationship between outness and well-being.

Experiences of concealment seem important to consider in the discussion of outness and disclosure for bisexual individuals. Pascale-Hague (2015) interviewed 12 bisexual participants about their sense of belonging and found participants sometimes felt they have to conceal their bisexual identity in order to achieve belongingness within sexual minority communities. One way bisexual people may conceal their bisexual identity is by allowing others to assume they are lesbian/gay or heterosexual (Pascale-Hague, 2015). Concealment of one's bisexuality in this way likely had a negative impact on their sense of authenticity (Pascale-Hague, 2015). Even though disclosure was not a significant predictor of the measured psychological outcomes in Schrimshaw et al.'s (2013) study described above, concealment was a significant predictor of depression symptoms $(\beta=.27, p<.01)$, anxiety symptoms $(\beta=.29, p<.01)$, and positive affect $(\beta=-.18, p<.05)$ when controlling for various demographics (e.g. race, income, etc.). Mereish, Katz-Wise, and Woulfe (2017) examined the minority stress model specifically for bisexual individuals and also included concealment as a proximal stressor in the model. Their results from a sample of 503 bisexual adults indicated that concealment was related to greater psychological distress through the mediating variable of loneliness (Mereish et al., 2017). This finding demonstrates evidence of a more nuanced relationship between concealment and psychological outcomes for bisexual individuals than a direct relationship is able to offer.

However, most of these studies fail to investigate if there are distinctions between bisexual individuals' outness as nonheterosexual and specifically as bisexual. The degree to 
which a bisexual person engages in disclosure and concealment may produce stress not only when considering disclosing or concealing their identity as nonheterosexual, but also specifically as bisexual. Instead, these studies either employ measures of outness that simply ask bisexual participants to report their outness as nonheterosexual or as bisexual, but not both. This limitation likely leads to limited understanding of the additional stressors bisexual individuals face when navigating outness both as nonheterosexual and bisexual. Of note though is a finding by Mohr, Jackson, and Sheets (2016) in which they administered the OI (Mohr \& Fassinger, 2000) to a sample of 240 bisexual men and women twice; once cueing them to consider their outness as nonheterosexual and again as bisexual. Mohr et al. (2016) found bisexual participants reported significantly greater outness as a nonheterosexual individual compared to their outness as bisexual. Keeping this finding in mind, it seems beneficial to examine bisexual individuals' outness in terms of specifically being out as bisexual, above and beyond one's outness as nonheterosexual, when trying to understand their unique experiences of minority stress.

\section{Role of Authenticity}

The frequent erasure and invisibility of bisexuality along with common societal assumptions that being bisexual is an invalid or temporary identity (Brewster \& Moradi, 2010) portrays bisexuality as an inauthentic way of being. Given the societal context of bisexuality being deemed inauthentic, achieving authenticity in one's bisexual identity is likely not without its hurdles. Nonetheless, research reports authenticity as a salient construct in the lives of bisexual individuals (Brownfield et al., 2018; Scales Rostosky, Riggle, Pascale-Hague, \& McCants, 2010). In a recent qualitative study examining the positive 
changes bisexual people noticed after coming out as bisexual, all participants $(n=13)$

reported having a greater sense of authenticity (Brownfield et al., 2018). The unanimous reports of authenticity demonstrate the importance of authenticity in the lives of bisexual people.

In addition, bisexual individuals report that when authenticity is achieved, emotional and psychological benefits are evident (Pascale-Hague, 2015). More specifically, achieving authenticity has been reported to positively contribute to bisexual individuals' sense of community belonging and can influence their ability to establish meaningful relationships (Pascale-Hague, 2015). Many bisexual individuals considered authentic experiences to include being correctly identified as bisexual and did not want to be erased and seen as lesbian/gay or heterosexual (Pascale-Hague, 2015). Also, feelings of authenticity can help bisexual people obtain greater emotional and psychological strength (Pascale-Hague, 2015). Although sparse, these foundational studies elucidate the influence that authenticity may have on bisexual individuals' well-being, and steer future researchers to further examine the role authenticity plays in bisexual health.

\section{Purpose Statement}

The minority stress model proposes a relationship between minority stress experiences (e.g. disclosure and concealment) and psychological distress that is moderated by identity characteristics (Meyer, 2003). Research has tested this model with sexual minority individuals (Brewster et al., 2016; Lehavot \& Simoni, 2011), and has even found it applicable with bisexual individuals such that various proximal and distal stressors have been found to predict mental health outcomes (Brewster et al., 2013; Dyar et al., 2014, Lambe, 
Cerezo, \& O'Shaughnessy, 2017; Watson et al., 2016). Additionally, authenticity regarding one's LGB identity appears to play a role in the relationship between outness (using the OI), concealment, and well-being (Riggle et al., 2017). More specifically, authenticity positively correlated with outness and well-being and negatively correlated with concealment (Riggle et al., 2017). Authenticity also significantly predicted greater well-being when controlling for outness and concealment (Riggle et al., 2017). Findings with samples of gay men demonstrated authenticity served as a mediator between concealment and well-being (Birichi, 2015), and showed a moderated mediation (moderated by race) in the link from verbal disclosure to authenticity to well-being (Villicana, 2016). Nonetheless, studies have yet to consider the role of authenticity in this relation among bisexual people.

When determining whether a variable may be a moderator instead of a mediator, it is important to examine the relationship between the predictor and outcome variable (Frazier, Tix, \& Barron, 2004). For instance, if there are inconsistent results for the direct relationship between the predictor and outcome variable, there is likely a moderator that can explain these findings. Mediation, however, is usually derived from consistent findings of a relationship between the predictor and outcome variables and a desire to better understand how this relationship is occurring. Yet, Frazier et al. (2004) explained that the same variable may be analyzed as a moderator or a mediator, depending on the existing literature and theoretical grounding. When this is the case, a direct relationship between the predictor and outcome variable in the mediation does not serve as a necessary condition for mediation to occur.

Given the mixed findings in the direct relationship between outness and well-being, it seems there may be additional information that mediation cannot account for, and that testing 
authenticity as a moderator would also be worthwhile. When looking back at Meyer's proposed theory, he suggested that identity characteristics moderate the proximal stressorpsychological outcome relationship. Keeping in mind that authenticity is defined as an intrapersonal process, authenticity may be considered a characteristic of minority identity. As such, it may moderate the relationship between a proximal stressor (such as outness) and psychological outcomes. Also, given that consistent findings between a predictor (e.g. outness) and outcome variable (e.g. well-being) are not always necessary to test for mediation, and that previous research has found authenticity to serve as a mediator in the outness-well-being relationship, assessing the potential of authenticity as a mediator in the outness-well-being link could be beneficial.

The proposed study expects to expand the literature by examining the applicability of minority stress theory for bisexual individuals. More specifically, it will examine the relations among outness as bisexual (in terms of disclosure and concealment, separately), authenticity, and well-being. This study will assess the role of authenticity as a mediator and moderator, separately, in the relationship between outness and well-being.

The proposed study will examine the potential moderating and mediating effect of authenticity on the relationship between outness and well-being in order to better understand the diverse findings on this relationship. If moderation is found, these results will demonstrate that a relationship between outness (disclosure and/or concealment) does not influence well-being across all bisexual individuals. Instead, interventions aimed at helping bisexual individuals achieve authenticity (through a variety of tactics, which do not always have to include greater outness) will likely be more beneficial versus perpetuating the notion 
that greater outness as bisexual is necessary for healthy functioning. If mediation is found, these results will call for interventions that aid bisexual individuals in achieving both greater outness and greater authenticity instead of focusing on just one part in the link to well-being. Specifically, it would seem fruitful to explore with bisexual clients different ways they can achieve outness that allows them to feel more authentic. 


\section{CHAPTER 2}

\section{MANUSCRIPT}

\section{Introduction and Review of the Literature}

A central tenet in counseling psychology is to work with strengths and focus on positive functioning (Gelso, Nutt Williams, \& Fretz, 2014). Popularization of the term positive psychology by Martin Seligman furthered the amount of attention given to positive functioning (Gelso et al., 2014). Seligman and Csikszentmihalyi (2000) expounded upon this term when they introduced a three-pillar, strengths-perspective framework, stating that positive psychology includes three domains. The first pillar consisted of positive subjective experiences such as positive emotions, the second pillar contained positive individual traits such as various character strengths and virtues (e.g. authenticity), and the third pillar captured positive institutions and communities that foster the first two pillars. By examining research questions housed in one or more of these pillars, counseling psychologists can contribute to positive psychology research.

Similar to counseling psychology research broadly, a majority of LGBT-focused research is conceptualized from a deficit model (Vaughan et al., 2014). This occurrence is particularly evident in the frequency of distress and dysfunction serving as outcome variables in LGBT research. In efforts to foster a more balanced narrative of LGBT experiences, Vaughan et al. (2014) made a call for more positive psychology LGBT research studies and

offered a content analysis of existing studies. Specifically, Vaughan et al. (2014) pointed to Seligman and Csikszentmihalyi’s (2000) three-pillar, strengths-perspective model as a framework for conducting LGBT positive psychology research. They suggested LGBT 
researchers investigate factors encompassed in one or more of the three pillars as the implications of such research may assist in depathologizing and affirming LGBT identities. Vaughan et al. (2014) also noted there has been minimal attention directed at investigating the specific experiences of bisexual, queer, transgender, and LGBT people of color compared to lesbian and gay individuals within LGBT positive psychology studies. This gap in the literature points to a need for the study of positive psychology factors within specific LGBT groups, such as bisexual individuals. It is important to keep in mind the unique stressors faced by bisexual individuals, such as the discrimination encountered by both the heterosexual/straight community and the lesbian/gay community and societal messages of bisexuality being a phase or inauthentic identity (Brewster \& Moradi, 2010). Thus, it seems imperative to examine the ways in which bisexual individuals are thriving despite this societal context.

\section{Bisexual Identities}

The identity label of bisexual is utilized as a "Community Identity Label" that can encompass a multitude of non-monosexual identity labels such as pansexual and queer (BiNetUSA, 2015, p. 3). In addition to the community label of bisexual, some bisexual people use "Personal Identity Labels" in order to better capture their sexuality (BiNetUSA, 2015, p. 3; Dyar, Feinstein, \& London, 2015). Someone may identify broadly with the community label of bisexual, but more specifically define themselves as pansexual or queer. Keeping this in mind, researchers studying bisexual individuals have begun offering bisexual participants space to report additional identity labels if they believe the term 'bisexual' does 
not fully capture their identity (Brownfield, Brown, Jeevanba, \& VanMattson, 2018; Watson et al., 2016).

A recent report assembled by the Movement Advancement Project (MAP) detailed that $5.5 \%$ of women and $2 \%$ of men in the U.S. identify as bisexual, and of people in the U.S. who identify as either L, G, or B, 52\% of them identify as bisexual (2016). Despite the abundance of bisexual individuals (sometimes referred to as the "invisible majority") in the U.S. LGB population, their experience and health needs are rarely studied separately from LG individuals (MAP, 2016). This lack of attention to research on bisexual-specific samples not only results in the unique experiences and needs of bisexual individuals being rendered invisible, but also paints an inaccurate portrayal of LG individuals' experiences and needs.

\section{Minority Stress Theory}

Meyer (2003) presented a minority stress model outlining the association between minority-specific stressors and mental health outcomes for sexual minority individuals (lesbian, gay, bisexual, queer). Specifically, Meyer explained how both distal and proximal stressors make up minority stress experiences. Distal stressors are external experiences, such as discrimination experiences, whereas proximal stressors are internal experiences, such as internalized homophobia/biphobia, outness, and concealment. Meyer proposed that the more sexual minority individuals experience minority stressors, the more they will experience psychological distress. Since the minority stress model's introduction to the field, research continued to validate the proposed relationship between minority stressors (both distal and proximal) and mental health outcomes for sexual minority people (Brewster, Velez, Foster, Esposito, \& Robinson, 2016; Lehavot \& Simoni, 2011). However, researchers have 
expressed concerns with conducting research that reports bisexual experiences in aggregate to monosexual, sexual minority experiences (lesbian and gay experiences; Galupo, Mitchell, \& Davis, 2015). Despite this call for bisexual-specific research initiatives, few studies exist in the literature examining the application of minority stress theory specifically for bisexual individuals (Brewster, Moradi, DeBlaere, \& Velez, 2013; Dyar et al., 2015, Lambe, Cerezo, \& O'Shaughnessy, 2017; Watson et al., 2016).

\section{Minority Stress for Lesbians and Gay Men}

\section{Role of outness, disclosure, and concealment. A proximal stressor commonly}

studied in relation to psychological distress and well-being is outness. Oftentimes, outness is defined as the degree to which others know about one's sexual orientation and/or the degree to which one has disclosed their identity to others (Riggle, Rostosky, Black, \& Rosenkrantz, 2017). Previous studies have reported associations between outness and well-being such that greater outness relates to greater well-being for lesbian, gay, and bisexual (LGB) individuals (Morris, Waldo, \& Rothblum, 2001). Yet greater outness being advantageous for LGB people's mental health is not always the case. Numerous studies have reported outness predicting negative mental health outcomes (Brewster et al., 2013; Roberts, Horne, \& Hoyt, 2015). Given the inconsistent findings in the relationship between outness and mental health outcomes, it appears other factors may be mediating or moderating this relationship.

Thus, various factors likely play a role in the relationship between minority stressors, such as outness and mental health outcomes. Meyer (2003) noted that someone's LGBrelated coping and social support could soften the impact of minority stressors on their mental health outcomes. Also, the characteristics of one's minority identity (such as the 
salience, valence, integration of their LGB identity) could modify the relationship between proximal stressors (such as outness) and mental health outcomes so that the relationship is strengthened or weakened (Meyer, 2003). For example, proximal stressors resulted in worse mental health outcomes for someone with a high level of LGB identity salience compared to someone with a low level of salience (Thoits, 1999). See Appendix A for figure of minority stress model.

The association between outness and well-being has also been reported when specifically studying the experiences of bisexual individuals (Brewster et al., 2013). Of note, however, though is a study by Mohr et al. (2016) in which they administered the Outness Inventory (OI; Mohr \& Fassinger, 2000) to bisexual participants twice; once cueing them to consider their outness as nonheterosexual and a second time as bisexual. Mohr, Jackson, and Sheets (2016) found bisexual participants reported significantly greater outness as a nonheterosexual individual compared to their outness specifically as bisexual. Given these results, it seems important to examine bisexual individuals' outness in terms of specifically being out as bisexual, above and beyond one's outness as nonheterosexual, when trying to understand their unique experiences of minority stress.

The OI conceptualized greater outness as having greater verbal disclosure(s), and placed non-verbal disclosure(s) as a stepping-stone to verbal disclosure(s), and did not measure any form of concealment. Whereas verbal disclosure is the degree to which one's sexual orientation is known and discussed with others, non-verbal disclosure would be the degree to which others know about one's sexual orientation but do not discuss it (Mohr \& Fassinger, 2000; Villicana, Delucio, \& Biernat, 2016). However, research comparing the 
relationship between verbal disclosure (using the OI) and well-being for gay White men and gay Latino men showed differences in this relationship, suggesting the relationship between outness and mental health outcomes may vary by race and ethnicity (Villicana et al., 2016). Interaction effects between ethnicity and verbal disclosure on well-being revealed no relationship between verbal outness (OI scores) and well-being for gay Latino men, but there was a positive relationship between these variables for gay White men such that greater verbal disclosure was positively related to greater psychological wellness (Villicana et al., 2016). More specifically, the authors note how at levels of low verbal disclosure, gay Latino men reported greater well-being than gay White men. These findings capture how outness, when more narrowly conceptualized as verbal dislosure(s), was not a predictor of well-being for all gay men (Villicana et al., 2016). In addition, these findings reveal that being verbally out to others is not a necessity that all gay individuals must enact in order to achieve wellbeing, and these findings dispel the White gay narrative often perpetuated onto all gay men of greater verbal outness being directly beneficial to well-being. Thus, it is imperative that outness be examined with an intersectional lens.

The potential applicability of these cultural differences for the bisexual community seem important given that people of color, compared to White individuals, are more likely to identify as bisexual (MAP, 2016), and $21 \%$ of bisexual men identify as Hispanic (Herek, Norton, Allen, \& Sims, 2010). As such, the selection of outness measures that abstain from organizing different styles of disclosure (verbal vs. non-verbal) along a hierarchy would be an important consideration when conducting research on bisexual participants. When using the OI, one's degree of verbal disclosure receives a higher score than one's degree of non- 
verbal disclosure. In other words, when using the OI, participants who engage in any level of verbal disclosure are classified as having greater outness than those who only use non-verbal disclosure tactics. Measurement considerations aside, Villicana et al.'s (2016) findings seem valuable to bisexual research given the racial/ethnic diversity in the bisexual population and a need to better understand how and when disclosure predicts well-being from an intersectional lens. Thus, examining potential moderators in the relationship between disclosure and wellbeing would help paint a more nuanced understanding of this relationship, instead of assuming a direct relationship between disclosure and well-being for bisexual individuals.

Outness is often measured as either the degree one discloses their sexual orientation or one's degree of concealment. Meidlinger and Hope (2014) explained the distinctions between disclosure and concealment in that disclosure refers to actively sharing one's sexual orientation (verbally or non-verbally), and concealment refers to actively avoiding one's sexual orientation being shared. Furthermore, Meidlinger and Hope (2014) identified outness as a construct consisting of both these factors (disclosure and concealment). Nonetheless, researchers have repeatedly confused the distinctions in these constructs, oftentimes measuring outness only within the context of either disclosure or concealment, not both (Brewster et al., 2013; Watson et al., 2016).

Prior research that has examined both disclosure and concealment among LGB individuals revealed a negative association between concealment and well-being (i.e. psychological wellness and positive functioning) and a positive association between disclosure and well-being (Riggle et al., 2017). Studies continue to demonstrate the distinction between disclosure and concealment as separate constructs (Jackson \& Mohr, 
2016; Meidlinger \& Hope, 2014). Meidlinger and Hope (2014) developed a new measure (Nebraska Outness Scale; NOS) with a sample of 192 LGB participants in order to examine if these separate aspects of outness, disclosure and concealment, could be conceptually combined as a single-factor representation of outness. According to Meidlinger and Hope, the NOS better reflects the distinctions between disclosure and concealment as related but separate processes that can be combined to understand one's degree of outness.

Role of authenticity. Another factor to consider in discussions of outness, disclosure, and concealment is authenticity, which refers to the intrapersonal experience of being true to one's sense of self and one's values (Riggle et al., 2017). Riggle et al. (2017) explained that authenticity may relate to one's decisions about disclosing or concealing their sexual orientation. For example, one may work towards greater disclosure or less concealment as a way to obtain greater authenticity (Szymanski, Mikorski, \& Carretta, 2017). The authenticity achieved by LG individuals also appeared to positively influence their well-being. A lesbian participant noted, "I am living authentically, which feeds my confidence, my joy and happiness, my relationship with God, my improved health” (Riggle, Whitman, Olson, Rostosky, \& Strong, 2008, p. 213). Thereby it seems that authenticity may serve as a predictor to mental health for $L G$ individuals.

Continued efforts to study the role of authenticity for LGB individuals led Riggle, Mohr, Rostosky, Fingerhut, and Balsam (2014) to develop a multifactor positive identity measure (referred to as the LGB-Positive Identity Measure; LGB-PIM). A five-item subscale capturing LGB people's experiences of authenticity arose in the scale development results. In a more recent study using the LGB-PIM authenticity subscale, Riggle et al. (2017) found that 
authenticity uniquely positively predicted psychological well-being for LGB individuals when controlling for outness (defined as disclosure), concealment, and education. This significant finding suggests that authenticity plays a unique role in LGB people's experiences of well-being.

\section{Minority Stress for Bisexual Adults}

When describing a model for minority stress, Meyer (2003) emphasized that bisexual individuals likely experience minority stressors differently than gay and lesbian individuals. His reasoning for this is grounded in evidence from a large community survey assessing the mental health of LGB individuals. Results of the survey showed bisexual individuals reported a greater number of stressors and mental health concerns than gay and lesbian individuals (Jorm, Korten, Rodgers, Jacomb, \& Christensen, 2002). It seems likely that the increased mental health concerns reported by bisexual adults could be a result of bisexual individuals not only navigating stressors related to one's same-gender attraction, but also related to one's ability to feel attraction to multiple genders. In other words, bisexual individuals are faced with stressors stemming from homophobia/heterosexism and biphobia/monosexism. To illuminate this experience consider that a bisexual person may encounter stress in response to others' negative attitudes regarding someone having same-sex attractions and they may feel stress in response to others' beliefs that bisexuality is not real or valid. However, a gay or lesbian person may encounter similar stress from others' negative attitudes regarding same-sex attractions, but they would not experience stress from the latter. Encountering discrimination from both the heterosexual/straight community and the LG community surfaces as another unique minority stressor for bisexual individuals (Brewster \& 
Moradi, 2010; Mitchell, Davis, \& Galupo, 2015; Roberts, Horne, \& Hoyt, 2015). The impact of these additional bisexual-specific stressors is reflected in the higher rates of mental health concerns for bisexual adults compared to LG adults (Molina, Marquez, Logan, Leeson, Balsam, \& Kaysen, 2015).

Role of outness, disclosure, and concealment. A specific stressor that bisexual individuals navigate is their level of outness (i.e. experiences of disclosure and/or concealment). Several studies have made efforts to better understand the minority stress experiences of bisexual individuals' in regards to their levels of outness (Brewster et al., 2013; Molina et al., 2015; Roberts et al., 2015). These studies offer a foundational conceptualization of outness as a minority stressor for bisexual individuals.

For instance, when studying the role of minority stressors on mental health in a sample of bisexual adults, Brewster et al. (2013) found a significant positive correlation between one's outness as bisexual (as measured by the OI) and their psychological wellbeing. Their results also revealed outness as bisexual served as a partial mediator between antibisexual prejudice (a distal stressor) and well-being (Brewster et al., 2013). This mediation demonstrated that greater antibisexual prejudice predicted greater outness, which then predicted greater well-being (Brewster et al., 2013). Thus, outness as bisexual appears to be related to both benefits (such as greater well-being) and risks (such as greater prejudice).

There is research that has successfully teased apart the conceptual differences between outness, disclosure, and concealment for bisexual individuals. Schrimshaw, Siegal, Downing, and Parsons (2013) investigated relationships between disclosure and concealment (as separate variables) on mental health outcomes in a sample of 203 non-gay-identified, 
bisexually-behaving men. Results revealed that disclosure (as assessed with a measure different from the OI) did not significantly predict any of the three psychological outcome variables measured (depression symptoms, anxiety symptoms, positive affect).

These research findings offer mixed results regarding the relationship between outness (using the OI or other disclosure-only measures) and psychological outcomes for bisexual individuals. These mixed findings warrant researchers to continue examining the impact of outness for bisexual individuals. In particular, these findings highlight the need to include more expansive definitions of outness (other than simply measuring disclosure) and/or the role of additional variables in the relationship between outness and well-being. Experiences of concealment seem important to consider in the discussion of outness and disclosure for bisexual individuals. One way bisexual people may conceal their bisexual identity is by allowing others to assume they are lesbian/gay or heterosexual (Pascale-Hague, 2015). Concealment of one's bisexuality in this way likely had a negative impact on their sense of authenticity (Pascale-Hague, 2015). Even though disclosure was not a significant predictor of the measured psychological outcomes in Schrimshaw et al.'s (2013) study described above, concealment was a significant predictor of depression symptoms, anxiety symptoms, and positive affect when controlling for various demographics (e.g. race, income, etc.). Mereish, Katz-Wise, and Woulfe (2017) examined the minority stress model specifically for bisexual individuals and also included concealment as a proximal stressor in the model. Their results from a sample of bisexual adults indicated that concealment was related to greater psychological distress through the mediating variable of loneliness (Mereish et al., 2017). This finding demonstrates evidence of a more nuanced relationship 
between concealment and psychological outcomes for bisexual individuals than a direct relationship is able to offer.

However, most of these studies fail to investigate if there are distinctions between bisexual individuals' outness as nonheterosexual and specifically as bisexual. The degree to which a bisexual person engages in disclosure and concealment may produce stress not only when considering disclosing or concealing their identity as nonheterosexual, but also specifically as bisexual. Instead, these studies either employ measures of outness that simply ask bisexual participants to report their outness as nonheterosexual or as bisexual, but not both. This limitation likely leads to limited understanding of the additional stressors bisexual individuals face when navigating outness both as nonheterosexual and bisexual. Of note though is a finding by Mohr et al. (2016) in which they administered the OI (Mohr \& Fassinger, 2000) to a sample of bisexual men and women twice; once cueing them to consider their outness as nonheterosexual and again as bisexual. Mohr et al. (2016) found bisexual participants reported significantly greater outness as a nonheterosexual individual compared to their outness as bisexual. Keeping this finding in mind, it seems beneficial to examine bisexual individuals' outness in terms of specifically being out as bisexual, above and beyond one's outness as nonheterosexual, when trying to understand their unique experiences of minority stress.

Role of authenticity. The frequent erasure and invisibility of bisexuality along with common societal assumptions that being bisexual is an invalid or temporary identity (Brewster \& Moradi, 2010) leads bisexuality to be portrayed as an inauthentic way of being. Given the societal context of bisexuality being deemed inauthentic, achieving authenticity in 
one's bisexual identity is likely not without its hurdles. Nonetheless, research reports authenticity as a salient construct in the lives of bisexual individuals (Brownfield et al., 2018; Scales Rostosky, Riggle, Pascale-Hague, \& McCants, 2010). In a recent qualitative study examining the positive changes bisexual people noticed after coming out as bisexual, all participants reported having a greater sense of authenticity (Brownfield et al., 2018). The unanimous reports of authenticity demonstrate the importance of authenticity in the lives of bisexual people.

In addition, bisexual individuals report that when authenticity is achieved, emotional and psychological benefits are evident (Pascale-Hague, 2015). More specifically, achieving authenticity has been reported to positively contribute to bisexual individuals' sense of community belonging and can influence their ability to establish meaningful relationships (Pascale-Hague, 2015). Many bisexual individuals considered authentic experiences to include being correctly identified as bisexual and did not want to be erased and seen as lesbian/gay or heterosexual (Pascale-Hague, 2015). Also, feelings of authenticity can help bisexual people obtain greater emotional and psychological strength (Pascale-Hague, 2015). Although sparse, these foundational studies elucidate the influence that authenticity may have on bisexual individuals' well-being, and steer future researchers to further examine the role authenticity plays in bisexual health.

\section{Present Study}

The minority stress model proposes a relationship between minority stress experiences (e.g. disclosure and concealment) and psychological distress that is moderated by identity characteristics (Meyer, 2003). Research has tested this model with sexual 
minority individuals (Brewster et al., 2016; Lehavot \& Simoni, 2011), and has even found it applicable with bisexual individuals such that various proximal and distal stressors have been found to predict mental health outcomes (Brewster et al., 2013; Dyar, Feinstein, \& London, 2014, Lambe et al., 2017; Watson et al., 2016). Additionally, authenticity regarding one's LGB identity has been reported to play a role in the relationship between outness (using the OI), concealment, and well-being (Riggle et al., 2017). More specifically, authenticity was found to positively correlate with outness and well-being and negatively correlate with concealment (Riggle et al., 2017). Authenticity also significantly predicted greater well-being when controlling for outness and concealment (Riggle et al., 2017). Findings with samples of gay men demonstrated authenticity served as a mediator between concealment and wellbeing (Birichi, 2015), and showed a moderated mediation (moderated by race) in the link from verbal disclosure to authenticity to well-being (Villicana et al., 2016). Nonetheless, studies have yet to examine authenticity in the minority stress framework with bisexual people.

When determining whether a variable may be a moderator instead of a mediator, it is important to examine the relationship between the predictor and outcome variable (Frazier, Tix, \& Barron, 2004). For instance, if there are inconsistent results for the direct relationship between the predictor and outcome variable, there is likely a moderator that can explain these findings. Mediation, however, is usually derived from consistent findings of a relationship between the predictor and outcome variables and a desire to better understand how this relationship is occurring. Yet, Frazier et al. (2004) explained that the same variable may be analyzed as a moderator or a mediator, depending on the existing literature and theoretical 
grounding. When this is the case, the need for a direct relationship between the predictor and outcome variable in the mediation does not serve as a necessary condition for mediation to occur.

Given the mixed findings in the direct relationship between outness and well-being, it seems there may be additional information that mediation cannot account for, and that testing authenticity as a moderator would be worthwhile. When looking back at Meyer's proposed theory, he suggested that identity characteristic moderate the proximal stressor-psychological outcome relationship. Keeping in mind that authenticity is defined as an intrapersonal process, perhaps authenticity can be considered a characteristic of minority identity. If so, it would fit within the minority stress model such that authenticity is a moderator in the relationship between a proximal stressor (such as outness) and psychological outcomes. Also, given that consistent findings between a predictor (e.g. outness) and outcome variable (e.g. well-being) are not always necessary to test for mediation, and that previous research has found authenticity to serve as a mediator in the outness-well-being relationship, assessing the potential of authenticity as a mediator in the outness-well-being link could be beneficial.

The current study examined the applicability of minority stress theory for bisexual individuals with particular attention to the relations among outness as bisexual (in terms of disclosure and concealment, separately), authenticity, and well-being. This study assessed the role of authenticity as a mediator and moderator, separately, in the relationship between outness and well-being. Specifically, I proposed the following hypotheses:

1. Disclosure as bisexual will explain a significant proportion of variance in wellbeing above and beyond what is explained by disclosure as nonheterosexual. 
2. Authenticity will mediate the positive relationship between disclosure as bisexual and well-being.

3. Authenticity will moderate the positive relationship between disclosure as bisexual and well-being, such that the interaction of disclosure as bisexual and authenticity will explain a significance proportion of variance in well-being above and beyond what is explained by disclosure as bisexual and authenticity. Specifically, authenticity will create an enhancing effect on disclosure; the slope of the relationship between disclosure and wellbeing increases at higher levels of authenticity.

4. Concealment as bisexual will explain a significant proportion of variance in wellbeing above and beyond what is explained by concealment as nonheterosexual.

5. Authenticity will mediate the negative relationship between concealment as bisexual and well-being.

6. Authenticity will moderate the negative relationship between concealment as bisexual and well-being, such that the interaction of concealment as bisexual and authenticity will explain a significant proportion of variance in well-being above and beyond what is explained by concealment as bisexual and authenticity. Specifically, authenticity will create an enhancing effect on concealment; the slope of the relationship between concealment and well-being increases at higher levels of authenticity.

\section{Method}

\section{Participants}

The obtained sample consisted of 450 participants that met the following eligibility criteria: (1) were 18 years of age or older, (2) self-identified as bisexual, and (3) resided in 
the United States. A power analysis for hypotheses 1, 2, 4, and 5 with an anticipated effect size for each of .047, alpha level of .05, and power of .80, revealed a need for 209 participants. A power analysis for hypotheses 3 and 6 with an anticipated effect size of .02, alpha level of .05, and power of .80 called for 395 participants. Thus, I planned and succeeded in recruiting a minimum of 302 participants, which is the average number of participants needed across the various power analyses. Participants ranged in age from 18 to 70 years with an average age of $30.40(S D=8.72)$. Regarding sexual identity, participants were invited to write-in additional sexual identity labels if they felt the label of bisexual did not fully encompass their identity. Two-hundred and thirty-six participants (52.4\%) took the opportunity to write more about their sexual identity label(s). Labels that were commonly reported were pansexual $(n=86,19.1 \%)$, queer $(n=90,20 \%)$, and asexual, ace, or demisexual $(n=12,2.7 \%){ }^{1}$

Participants were asked to identify their gender via a write-in option. Their gender representation included 175 women, 71 men, 12 transgender women, 28 transgender men, 81 cisgender women, 11 cisgender men, 40 non-binary (e.g., gender fluid, bigender, etc.,), 14 gender queer, 6 agender, 1 questioning, and 8 participants described their gender as other (e.g., androgynous).

Three-hundred and twenty-three participants (71.8\%) identified as Non-Hispanic White, 28 (6.2\%) identified as Hispanic/Latino/Latina/Latin@/Latinx, 24 (5.3\%) identified as Asian/Pacific Islander, 22 (4.9\%) identified as Multiracial/ethnic, 14 (3.1\%) identified as

\footnotetext{
${ }^{1}$ Percentages are reported as the percentage out of the 450 participant total. Percentages can add up to over $100 \%$ given participants were able to write in multiple labels.
} 
Black/African American, four (0.9\%) identified as Middle Eastern, and two (0.4\%) identified as Native American/American Indian. Twenty-nine participants (6.4\%) felt the aforementioned terms did not adequately describe their race/ethnicity/cultural identity and thus elected to use their own words. These participants identified as third culture kid, Black/AfroCaribbean, Jewish, Chicana, Scandinavian, and South Asian, to name a few. Four participants (0.9\%) did not report their racial/ethnic/cultural identity.

Five (1.1\%) participants reported completing some high school and received no diploma, 17 (3.8\%) earned a high school diploma, 74 (16.4\%) attended some college and received no degree, $25(5.6 \%)$ received an associate degree, 150 (33.3\%) a bachelor's degree, $108(24 \%)$ a master's degree, $62(13.8 \%)$ a doctorate degree, $6(1.3 \%)$ attained a specialist degree. The remaining three participants $(0.7 \%)$ did not report their highest level of education. When asked about relationship status, participants reported the following: single ( $n=136,30.2 \%$ ), in a monogamous relationship (i.e. only dating one person; $n=89,19.8 \%$ ), in a non-monogamous dating relationship (i.e. dating more than one person; $n=22,4.9 \%$ ), polyamourous $(n=53,11.8 \%)$, partnered $(n=43,9.6 \%)$, married $(n=92,20.4 \%)$, married/partnered but separated $(n=3,0.7 \%)$, divorced $(n=5,1.1 \%)$, widowed $(n=1$, $0.2 \%)$, and six participants (1.3\%) did not report their relationship status.

\section{Procedure}

After approval from the institutional review board, I initiated recruitment. Participants were recruited from a variety of bisexual-specific and LGBTQ-related listservs and social media sites such as Facebook and reddit.com. Additionally, I recruited from a variety of online cultural communities (e.g. groups for people of color, persons with disabilities, etc.) to 
better obtain a representative sample and reach participants who may not be as connected to bisexual-specific or LGBTQ-related online communities. These recruitment efforts entailed sending an IRB-approved recruitment email to listserv moderators. In the email, I asked moderators for permission to distribute my recruitment advertisement. If approval was received, I shared a brief description of the study, the three criteria for eligibility along with the definition of bisexuality offered by Eisner (2013), and the study's hyperlink. Postings to social networking sites included the same information as that distributed through the listservs (brief description, eligibility criteria, and hyperlink).

The hyperlink directed participants to the online questionnaire that was administered via university-approved hosting website (Qualtrics). First, participants were provided information regarding the study purpose, my contact information and that of my advisor, and contact information for UMKC's IRB. At the bottom of this first page, participants read a statement indicating that if they clicked "Next" they were consenting to participate in the study. Upon clicking "Next" at the bottom of the first page, participants were asked to answer three yes-or-no questions: (1) are you at least 18 years of age or older, (2) do you identify as bisexual (along with Eisner's [2013] definition of bisexual), and (3) do you reside in the United States? If yes was selected for all three of these questions, participants met eligibility criteria and were asked to complete a demographics page (See Appendix B) and the measures described below. The two versions of the Nebraska Outness Scale (NOS; nonheterosexual and bisexual versions) were always presented one after another, and the order of these two measures were randomized. The remaining measures and demographics page were randomized with the set of NOS measures. The survey took approximately 15 
minutes to complete. At the end of the survey, participants had the option of entering a raffle to win one of ten $\$ 25$ amazon.com e-gift cards via a separate Qualtrics survey; on this survey, those who entered the raffle listed their email address.

\section{Measures}

Outness (Disclosure and Concealment). An adapted version of the 10-item Nebraska Outness Scale (NOS; Meidlinger \& Hope, 2014) was used to assess outness. The NOS measures two different dimensions of outness: disclosure (5 items) and concealment (5 items) and these two subscales were examined separately for the present study. The original NOS asks participants to rate their degree of disclosure and concealment in various social spheres (e.g., members of immediate family, people at school/work) on an 11-pt Likert-type scale where $0 \%=0$ points and $100 \%=10$ points for the disclosure scale and Never avoid $=0$ points and Always avoid $=10$ points for the concealment scale. The original scale's social sphere item for both the disclosure and concealment subscales, which inquire about "People you socialize with (e.g., friends and acquaintances)" was adapted into three items for the present study; one which read "Heterosexual/Straight people you socialize with...," one which read "Lesbian/Gay people you socialize with...", and one which read "Bisexual people you socialize with..." This resulted in each subscale having seven items. However, because some bisexual people may not have people in their lives that comprise each of these social groups, a not applicable (N/A) option was provided for each item stem.

For the items pertaining to disclosure, participants were asked "What percent of the people in this group do you think are aware of your sexual orientation?" and provided a scale that spans from $0 \%$ to $100 \%$ in increments of $10 \%$. Higher scores on this scale are indicative 
of greater disclosure. For the items pertaining to concealment, participants were asked "How often do you avoid talking about topics related to or otherwise indicating your sexual orientation?" and provided a scale with anchors of Never, Half of the time, and Always. Higher scores on this scale signify greater concealment. A participant's score on each subscale was then averaged across the number of responses provided by the participant. If a participant provided N/A for any items, that item(s) was not counted in the denominator of the mean equation. In doing so, higher scores became indicative of either greater disclosure or greater concealment.

Participants responded to the NOS twice with slight variations in instructions inspired by the procedures used for the OI in Mohr et al. (2016). This variation allowed for assessment of differences in outness when thinking about one's nonheterosexual identity (i.e. sexual minority identity) status versus one's bisexual identity status (See Appendix C). More specifically, participants were presented with the NOS instructions that ask participants to answer items in regards to their sexual minority identity. They were also presented the NOS with instructions asking them to respond to the items in regards to their bisexual identity.

Due to the number of adaptations made with the NOS for the present study, I requested input from multiple experts about these adaptations. Seven experts reviewed the adapted measure. These seven experts were selected based on having a bisexual/pansexual identity and/or having a history of conducting bisexual-related research. Two experts who identified as bisexual had received their doctoral degrees in psychology, and had published research on bisexual individuals. Three experts identified as bisexual or bisexual/pansexual and were psychology doctoral students who all had experience conducting bisexual-focused 
research. The remaining two experts who identified as bisexual were recruited through an online bisexual community resource. Three of the experts identified as White and the remaining four identified as Latina, Malaysian-Indian, Black, and Asian American. Four of the experts identified as cisgender women, two as cisgender men, and one as genderqueer.

The seven experts offered feedback about the wording and presentation of instructions, social sphere options, and recommended adding an N/A response option to the item stems. All experts indicated that the original friends/acquaintances item should be separated into three separate items (heterosexual/straight friends, lesbian/gay friends, and bisexual friends). Two of the experts recommended careful statistical treatment of this response option (making sure it is not conflated with a 0 value response, but instead treated as missing for a purpose). Recommendations were also made to bold and underline the words 'sexual minority' and 'bisexual' throughout the measure in order to make sure participants are properly cued and providing valid responses. Finally, all of the experts offered suggestions for possible bisexual-specific concealment behaviors that could be included in the NOS-C bisexual version instructions. These suggestions were reviewed with my dissertation committee chair and the most frequently named examples were included in the measure.

Good internal consistency reliability with previous LGB samples has been established for the original NOS full scale, disclosure subscale, and concealment subscale $(\alpha=.89, \alpha=$ .82 , and $\alpha=.80$, respectively; Meidlinger \& Hope, 2014). Convergent validity evidence has been established for the original NOS through statistically significant, large correlations of each NOS subscale and the full scale with the OI (Meidlinger \& Hope, 2014). Predictive 
validity evidence for the original NOS was assessed via statistically significant correlations with quality of life (Meidlinger \& Hope, 2014). For the present study, the Sexual Minority Disclosure, Sexual Minority Concealment, Bisexual Disclosure, and Bisexual Concealment scale all demonstrated good scale reliability with the obtained sample $(\alpha=.86, .86, .83, \&$ .85 , respectively).

LGB Authenticity. LGB Authenticity was measured with the Authenticity subscale of the LGB-Positive Identity Measure (LGB-PIM; Riggle et al., 2014). This subscale asked participants to report their feelings of authenticity regarding their LGB identity using a 7point scale ranging from 1 (strongly disagree) to 7 (strongly agree). Some examples of items include "I feel I can be honest and share my bisexual identity with others" and "I have a sense of inner peace about my bisexual identity." The full LGB-PIM contains five subscales (self-awareness, authenticity, community, intimacy, and social justice), each with five items. Higher scores in the authenticity subscale indicate greater authenticity. Good internal consistency reliability for scores on the five-item authenticity subscale with previous LGB samples has been established ( $\alpha=.88, \alpha=.82)$, as has evidence of convergent/discriminant validity (Riggle et al., 2014). More specifically, convergent validity was demonstrated with significant, positive correlations between the five-item authenticity subscale and an identity affirmation measure $(r=.67)$ and with an authentic living measure $(r=.46$; Riggle et al., 2014). Evidence for discriminant validity was examined with significant, negative correlations between the five-item authenticity subscale and a self-alienation measure ( $r=$ .38; Meidlinger \& Hope, 2014). 
For the present study, all LGB acronyms in the scale were adjusted to just read "bisexual." Given this adjustment in item language, the factor structure and item loading was assessed for the Authenticity subscale of the LGB-PIM (before the dataset was examined for missing data). In order to mirror procedures used in the development of the LGB-PIM and its subscales (Riggle et al., 2014), an exploratory factor analysis (EFA) using Maximum Likelihood (ML) was conducted. No rotation was selected as all 5-items were fixed to load to a single factor (authenticity). Using listwise deletion with a sample of 463 participants, results showed good sampling adequacy with the Kaiser-Meyer-Olkin (KMO) measure equaling .85. Bartlett's Test of Sphericity demonstrated it was appropriate to conduct a factor analysis, $x^{2}(10)=1215.96, p<.001$. All five items loaded to a single factor and accounted for $59.99 \%$ of the shared variance in the items. Each item loaded above the minimum factor loading of .45 established in the development of the scale (Riggle et al., 2014). Factor loadings ranged from .61 to .88 , and communalities ranged from .38 to .77 . Based on these findings, all 5 items were retained in the scale as each loaded around the pre-determined threshold. Internal consistency reliability of scores was found to be .87 .

Well-Being. Well-being was measured with the 42-item Psychological Well-Being Scale (PWBS; Ryff, 1989; see Appendix E). This scale included six aspects of well-being that were combined into a single-factor measure of well-being: positive relationships with others, personal growth, self-acceptance, purpose in life, autonomy, and environmental mastery. A six-point Likert scale ranging from 1 (strongly disagree) to 6 (strongly agree) allowed participants to rate how well each item described them. Example items include "When I look at the story of my life, I am pleased with how things have turned out" and "I 
have a sense of direction and purpose in life." Average scores range from 1 to 6 and were used for the present study where higher scores signify greater amounts of well-being. This 42-item version of the PWBS has shown good internal consistency reliability when used with LGB samples ( $\alpha=.95$; Riggle et al., 2017), and it duplicated past performance in the current study $(\alpha=.95)$. Correlations revealing significant, positive correlations between total scores of the PWBS and several pre-existing well-being measures, and negative significant correlations between total scores of the PWBS and negative functioning provide validity evidence (Ryff, 1989). Also, previous LGB studies utilized total PWBS scores over subscale scores across different versions of the PWBS (18 items, 42 items, 84 items; Riggle et al., 2017; Selvidge, Matthews, \& Bridges, 2008; Velez \& Moradi, 2016).

\section{Data Analysis}

\section{Data Screening}

At the end of data collection, 670 individuals accessed the survey. If participants answered 'no' to any of the three eligibility questions, they were directed to the end of the survey, thanked for their interest and told that they do not meet the eligibility criteria needed to participate. Forty-eight people were removed from the data file because they did not respond 'yes' or did not offer a response to all three of the inclusion criteria questions. There were also five items embedded in the survey to assess attentive responding. Specifically, participants were cued 'Please select 'Strongly Agree' for this item.” Participants needed to correctly respond to four of these five items in order to be retained in the final sample. When checking the data file for participants who correctly answered the embedded validity questions, another 156 participants were removed from the data file for failure to provide 4 
out of 5 correct responses. In total, 466 participants remained in the data file after checking for eligibility and attentive responding.

Next, missing data were assessed at the scale level. No participants were missing data for the bisexual disclosure scale, and two participants $(0.4 \%)$ were missing data for the bisexual concealment scale. For sexual minority outness, one participant $(0.2 \%)$ was missing data for the sexual minority disclosure scale, and two participants $(0.4 \%)$ were missing data for the sexual minority concealment scale. There were three participants $(0.6 \%)$ missing data for the 5-item authenticity scale. The outcome measure of well-being had $22(4.7 \%)$ participants missing data. Of the participants missing data, two were missing data on a second measure. Thus, across all these variables, there were 28 participants $(6 \%)$ missing data.

For the two participants missing data on the bisexual concealment scale, both participants had responded with "N/A" to all seven items on the scale. The participant missing data for the sexual minority disclosure scale did not respond to any of the seven items $(100 \%)$ on the scale. This same participant did not respond to any of the seven items $(100 \%)$ on the sexual minority concealment scale. Yet, the other participant missing data on the sexual minority concealment scale responded with "N/A" to all seven items on the scale. Among the three participants missing data on the authenticity scale, two of them did not respond to any of the five items $(100 \%)$, whereas the remaining participant was missing data for one item $(20 \%)$ of the scale. When looking at the 22 participants missing data on the well-being scale, three participants were missing 21 items (50\%) from the 42 -item scale (which seems to be a result of these three participants not completing the second page for this 
scale). Four participants were missing two items (4.8\%) on the well-being scale, and 15 participants were missing only one item $(2.4 \%)$ on the well-being scale. Across all items and participants (75 items x 466 participants $=34,950$ data points), there were 132 missing data points $(0.4 \%)$. These 132 data points were not missing completely at random, MCAR $\chi^{2}(4926)=5524.29, p<.001$.

Given the finding that missing data were not missing completely at random, group differences on the variables of interest (bisexual disclosure, bisexual concealment, sexual minority disclosure, sexual minority concealment, authenticity, and well-being) were conducted via independent samples t-tests between participants with complete data $(n=438)$ and the 28 participants with missing data. Results revealed no significant differences for bisexual disclosure $(t[464]=-1.21, p=.23)$, bisexual concealment $(t[462]=-.51, p=.61)$, sexual minority disclosure $(t[463]=.34, p=.74)$, sexual minority concealment $(t[462]=.30$, $p=.76)$, authenticity $(t[35.55]=1.12, p=.28)$, or well-being $(t[442]=1.38, p=.17)$ between participants with complete data and those with missing data. Even though data were not missing completely at random across the whole dataset, no significant group differences arose between participants missing data and those with complete data. Thus, I decided to look at missing patterns at the item-level per scale and imputed missing values based on each scale's items (i.e. distinct from the influence of other scales' items).

Imputation was then performed per scale at the item-level using Expectation Maximization (EM). Items were found to be missing at random for the five items included in the Authenticity measure, MCAR $\chi^{2}(4)=.32, p=.99$, and the 42-items included in the wellbeing measure, $\operatorname{MCAR} \chi^{2}(755)=790.35, p=.18$. Item imputation was not used for the 
disclosure and concealment scales due to missing data on these scales occurring exclusively at the entire scale level. Instead, participants that were missing data on the disclosure and concealment scales were removed from the dataset via listwise deletion $(n=3)$.

Next, I examined univariate descriptives and normality. Skewness and kurtosis values fell in acceptable limits $(<|3|$ and $<|10|$, respectively; Kline, 2011) for all variables of interest (i.e. Bisexual Disclosure, Bisexual Concealment, Sexual Minority Disclosure, Sexual Minority Concealment, LGB-PIM Authenticity, and PWBS). Z-scores were calculated to identify and remove univariate outliers (i.e. participants whose scale score fell in excess of 3.29 standard deviations from the mean; Tabachnick \& Fidell, 2014). No participants were identified as univariate outliers based on these criteria, and thus, all 463 participants remained in the dataset.

Collinearity was assessed via Pearson's correlations. Given that none of the correlations between variables rose above an absolute value of .90, there was no collinearity between variables (Tabachnick \& Fidell, 2014). I investigated for multivariate outliers using Mahalanobis distance at $p<.001$. Due to the fact that I have five predictor variables in my analyses, the Mahalanobis distance is evaluated as $\chi^{2}(5)=20.515$ (Tabachnick \& Fidell, 2014). Thirteen participants were identified as multivariate outliers with Mahalanobis distances greater than 20.515. Subsequently these thirteen participants were removed from the dataset, leaving 450 participants for analysis. I then created bivariate scatterplots to examine linearity. All independent variables (IVs) appeared to have linear relationships with the dependent variable (DV). Following inspection of linearity, a bivariate scatterplot was built to examine homoscedascity of residuals. By looking at the distribution of standardized 
residuals across standardized predicted values of the DV (i.e. PWBS), it appeared the assumption of homoscedasticity of variance was met. Finally, descriptive statistics and correlations for variables of interest with the finalized sample of 450 participants are reported in Table 1.

\section{Preliminary Analyses}

Correlational analyses were performed to check assumptions of bivariate relationships among variables included in moderation and mediation hypotheses. Evaluation of the magnitude of correlations followed Cohen's (1992) guidelines in which small, medium, and large correlations correspond to $r=.10, r=.30$, and $r=.50$, respectively. Sexual Minority Disclosure was strongly correlated with Bisexual Disclosure $(r=.85, p<$ $.01)$, moderately correlated with Authenticity $(r=.47, p<.01)$, and weakly (yet still significantly) correlated with Well-Being $(r=.18, p<.01)$. Sexual Minority Concealment was strongly correlated with Bisexual Concealment $(r=.82, p<.01)$, moderately correlated Authenticity $(r=-.44, p<.01)$, and weakly correlated with Well-Being $(r=-.19, p<.01)$. Bisexual Disclosure was strongly correlated with Authenticity $(r=.52, p<.01)$ and weakly correlated with Well-Being $(r=.24, p<.01)$. Bisexual Concealment was strongly correlated with Authenticity $(r=-.50, p<.01)$ and weakly correlated with Well-Being $(r=-.20, p<$ $.01)$. Authenticity was weakly correlated with Well-Being $(r=.29, p<.01)$. See correlations presented in Table 1.

\section{Assessing for Control Variables}

Generational and cohort differences exist in experiences of minority stress (Meyer, 2003), and education level has appeared as a covariate when looking at the relationship 
among outness, concealment, authenticity, and well-being in past research (Riggle et al., 2017). In response to these past findings, it was valuable to assess for the potential covariates of age and education level. To assess for these potential control variables, I examined relationships between these variables and the main variables of interest (nonheterosexual disclosure, nonheterosexual concealment, bisexual disclosure, bisexual concealment, authenticity, and well-being). First, education level was recoded into three dummy variables (some high school or completion of high school [ $n=22]$, some college or Associate's degree [ $n=99]$, and Graduate degree [ $n=176])$, with participants who had received a Bachelor's degree serving as the reference group $(n=150)$. Three participants were missing data for both education level and age. Bivariate correlations were performed to assess for relationships between these demographic variables (the three education level dummy variables and the variable of age) with the main variables of interest. All three education level dummy variables significantly correlated with well-being, but did not correlate with any other main variables of interest. The same pattern arose for correlations with age (i.e. age significantly, positively correlated with well-being, but did not significantly correlate with other variables of interest). See Table 1 for correlation results. In response to these significant findings only occurring for one of the main variables of interest (well-being), education level and age were not controlled for in the analyses.

\section{Centering Predictor Variables and Assessing Multicollinearity}

I computed centered variables (i.e. variable minus variable mean) for bisexual disclosure, bisexual concealment, and authenticity. In doing so, I could better interpret my regression findings. Then, I computed interaction terms using these centered variables: 
bisexual disclosure centered $\mathrm{x}$ authenticity centered, and bisexual concealment centered $\mathrm{x}$ authenticity centered. Multicollinearity was assessed in the final models (see Hypothesis testing section below).

\section{Primary Analyses}

Hypothesis 1. Hypothesis 1 stated that disclosure as bisexual would explain a significant proportion of variance in well-being above and beyond what is explained by disclosure as nonheterosexual. A linear regression with PWBS as the dependent variable was performed in which disclosure as nonheterosexual, and concealment as nonheterosexual were entered in Step 1, and disclosure as bisexual centered and concealment as bisexual centered were entered in Step 2. Findings from this analysis regarding disclosure are reported here, whereas findings regarding concealment are reported under hypothesis 4 .

Effect sizes for multiple regression analyses were identified as small $\left(R^{2}=.01\right)$, medium $\left(R^{2}=.09\right)$, or large $\left(R^{2}=.25\right)$ based on guidelines by Kline (2011). Model 1 was significant in predicting psychological well-being $(F(2,447)=9.90, p<.001)$ and had a small effect size $\left(R^{2}=.042\right)$. Disclosure as nonheterosexual was not a significant predictor of well-being. Adding the centered variables of bisexual disclosure and bisexual concealment in Step 2 produced a significant increase in predicting well-being, while still maintaining a small effect size $\left(\Delta F(2,445)=6.152, p=.002, \Delta R^{2}=.026\right)$. More specifically, centered bisexual disclosure ( $\beta=.270, p=.003)$ was a statistically significant, positive predictor of well-being. Higher degrees of bisexual disclosure predicted greater well-being. Disclosure as nonheterosexual was not a significant predictor of well-being. Findings from Step 2 were in support of hypothesis 1; bisexual disclosure significantly predicted the variance in well-being 
above and beyond what was explained by disclosure as nonheterosexual. The overall model of step 1 and 2 had a small effect size $\left(R^{2}=.068\right)$. More specifically, the effect size of bisexual disclosure was small $\left(s r^{2}=.018\right)$. In other words, bisexual disclosure explained $1.8 \%$ of the variance in well-being.

Hypothesis 2. Hypothesis 2 stated that authenticity would mediate the relationship between disclosure as bisexual and well-being. This hypothesis was tested using Frazier et al.'s (2004) recommended steps that were popularized by Baron and Kenny (1986). First (Step 1), a regression analysis was conducted to assess the relationship between the predictor variable (disclosure as bisexual) and the outcome variable (well-being). As discussed in Hypothesis 1 findings, centered disclosure as bisexual was found to be a significant, positive predictor of well-being $(\beta=.270, p=.003)$. Then, the relationship between the predictor variable (disclosure as bisexual centered) and mediator variable (authenticity centered) was analyzed by performing a regression with the predictor variable as a predictor and the mediator variable as the outcome variable. When controlling for sexual minority disclosure and sexual minority concealment, bisexual disclosure and bisexual concealment predicted a significant amount of variance in authenticity $\left(\Delta F(2,445)=25.2921 p<.001, \Delta R^{2}=.075\right)$. Within this model, bisexual disclosure $\left(\beta=.300, p<.001, s r^{2}=.023\right)$ and the covariate of bisexual concealment $\left(\beta=-.315, p<.001, s r^{2}=.030\right)$ were significant predictors of authenticity, both with a small effect size. Greater degrees of bisexual disclosure predicted greater authenticity, whereas greater degrees of the covariate bisexual concealment predicted less authenticity. As a final step, I then entered the mediator variable (centered authenticity) as a predictor to the outcome variable (well-being) while controlling for the predictor 
variable (centered disclosure as bisexual). This final model was significant, with a medium effect size $\left(F(5,444)=9.873, p<.001, R^{2}=.100\right)$, and the addition of authenticity produced a significant increase in predicting variance of well-being $(\Delta F(1,444)=15.739, p<.001$, $\left.\Delta R^{2}=.032\right)$. Centered bisexual disclosure $\left(\beta=.204, p=.025, s r^{2}=.010\right)$ and authenticity $(\beta$ $\left.=.220, p<.001, s r^{2}=.032\right)$ were statistically significant, positive predictors with small effect sizes for well-being in the final model. Increases in both bisexual disclosure and authenticity predicted greater well-being. Collinearity statistics were examined for the final model. All variables fell within appropriate cutoffs such that all tolerance values were $>.10$ and all VIF values were $<10$.

In response to the significant findings at each of the three aforementioned mediationtesting steps, I performed Hayes Process Macro (2013) Model 4 with well-being as the dependent variable, centered authenticity as the mediator, and centered bisexual disclosure as the independent variable. Nonheterosexual disclosure, nonheterosexual concealment, and centered bisexual concealment were entered as covariates. The mediational model was significant and had a medium effect size $\left(F(5,444)=9.874, p<.001, R^{2}=.100\right)$. The path from bisexual disclosure to authenticity was significant and positive (path a; $B=.166, S E=$ $.0422, p<.001)$, and the path from authenticity to well-being was significant and positive (path $\mathrm{b} ; B=.146, S E=.0367, p<.001$ ). The indirect effect of bisexual disclosure on wellbeing was significant and positive $(B=.024, S E=.0097,95 \% \mathrm{CI}[.0095, .0483])$, and this was further confirmed by the normal theory-based Sobel test $(Z=2.747, p=.006)$. The direct effect of bisexual disclosure on well-being (path c'; $B=.075, S E=.0332, p=.025$ ), and the total effect (path c; $B=.099, S E=.0332, p=.003$ ) were both significant and positive. In 
regards to effects of covariates on well-being, none of the covariates arose as having a significant effect. However, the covariate of bisexual concealment had a significant, negative effect on authenticity $(B=-.154, S E=.0342, p<.001)$. These findings revealed that hypothesis 2 was supported; authenticity partially mediated the relationship between bisexual disclosure and well-being. More specifically, greater degrees of bisexual disclosure predicted greater authenticity, which in turn predicted greater well-being. See Figure 1.

Hypothesis 3. Hypothesis 3 stated authenticity would moderate the relationship between disclosure as bisexual and well-being. To test this hypothesis (as well as hypothesis 6), I performed another hierarchical regression. This entailed adding a fourth block to the three-block model used in hypotheses 2 and 5. This fourth block contained the interaction terms of bisexual disclosure $\mathrm{x}$ authenticity and bisexual concealment $\mathrm{x}$ authenticity (see Table 2). The overall model was significant with a medium effect size $(F(7,442)=7.160, p$ $<.001, R^{2}=.102$ ), but the addition of the interaction terms did not significantly increase the amount of well-being variance explained in the model $\left(\Delta F(2,442)=.438, p=.646, \Delta R^{2}=\right.$ .002). Thus, hypothesis 3 was not supported; authenticity did not moderate the relationship between bisexual disclosure and well-being.

Hypothesis 4. Hypothesis 4 stated that concealment as bisexual would explain a significant proportion of variance in well-being above and beyond what is explained by concealment as nonheterosexual. As discussed under Hypothesis 1, Model 1 was significant in predicting psychological well-being $(F(2,447)=9.90, p<.001)$ and had a small effect size $\left(R^{2}=.042\right)$. Within this model, concealment as nonheterosexual $(\beta=-.128, p=.022)$ was a significant, negative predictor of well-being. Higher degrees of nonheterosexual 
concealment predicted less well-being. Adding the centered variables of bisexual disclosure and bisexual concealment in Step 2 produced a significant increase in predicting well-being, while still maintaining a small effect size $\left(\Delta F(2,445)=6.152, p=.002, \Delta R^{2}=.026\right)$. Concealment as nonheterosexual, and centered bisexual concealment were not significant predictors of well-being. In other words, concealment as bisexual did not surface as a significant predictor of well-being above and beyond concealment as nonheterosexual. Thus, hypothesis 4 was not supported.

Hypothesis 5. Hypothesis 5 stated that authenticity would mediate the relationship between bisexual concealment and well-being. Again, following the three-step model from Baron and Kenny, Hypothesis 4 revealed that bisexual concealment did not significantly predict well-being. As mentioned under Hypothesis 2, Step 2 of the mediation analysis showed that bisexual concealment $(\beta=-.315, p<.001)$ was a significant, negative predictor of authenticity. Greater degrees of bisexual concealment predicted less authenticity. As well, Step 3 performed under Hypothesis 2 demonstrated that centered authenticity $(\beta=.220, p<$ .001) was a significant, positive predictor of well-being in the final regression model. In other words, greater degrees of authenticity predicted greater degrees of well-being.

I again followed up on the three-step mediational findings by performing the Hayes PROCESS (2013) macro with Model 4. As mentioned under Hypothesis 2, the mediational model was significant with a medium effect size $\left(F(5,444)=9.874, p<.001, R^{2}=.100\right)$. The path from bisexual concealment to authenticity was significant and negative (path a; $B=-$ $.154, S E=.034, p<.001)$, and the path from authenticity to well-being was significant and positive (path $\mathrm{b} ; B=.146, S E=.037, p<.001$ ). Greater degrees of bisexual concealment 
predicted less authenticity, whereas greater degrees of authenticity predicted greater degrees of well-being. The indirect effect of bisexual concealment on well-being was significant and negative $(B=-.022, S E=.009,95 \%$ CI [-.044, -.009]), and this was further confirmed by the normal theory-based Sobel test $(Z=-2.94, p=.003)$. The direct effect of bisexual concealment on well-being (path c'; $B=-.002, S E=.027, p=.953$ ) and the total effect (path c; $B=-.024, S E=.027, p=.373$ ) were not significant. In regards to effects of covariates on well-being, bisexual disclosure arose as having a significant, positive effect $(B=.075, S E=$ $.033, p=.025)$. Bisexual disclosure also had a significant, positive effect on authenticity ( $B=$ $.166, S E=.042, p<.001)$. These findings revealed that hypothesis 5 was supported; authenticity mediated the relationship between bisexual concealment and well-being. More specifically, greater degrees of bisexual concealment predicted less authenticity, which is turn predicted less well-being. The direct effect of bisexual concealment on well-being was nonsignificant, indicating complete mediation. These results are shown in Figure 1.

Hypothesis 6. Hypothesis 6 stated that authenticity would moderate the relationship between concealment as bisexual and well-being. As described under hypothesis 2, this hierarchical regression model was significant with a medium effect size, but the addition of the interaction terms did not significantly increase the amount of well-being variance explained in the model. Thus, hypothesis 6 was not supported; authenticity did not moderate the relationship between bisexual concealment and well-being.

Summary. In summation, bisexual disclosure surfaced as a significant, positive predictor of well-being above and beyond sexual minority disclosure. The positive relationship between bisexual disclosure and well-being was significantly mediated by 
authenticity but was not moderated by authenticity. Bisexual concealment was not a significant predictor of well-being above and beyond sexual minority concealment. However, authenticity significantly mediated the relationship between bisexual concealment and wellbeing such that greater concealment predicted less authenticity, which in turn predicted less well-being. Authenticity did not moderate the relationship between bisexual concealment and well-being.

\section{Discussion}

This study examined the unique ability of bisexual disclosure and concealment to predict well-being and investigated the role of authenticity as a possible mediator and moderator among these variables. My results indicated that bisexual disclosure significantly predicted well-being above and beyond the ability of sexual minority disclosure to predict well-being. Greater degrees of bisexual disclosure predicted greater degrees of well-being in the present sample when controlling for participants' level of sexual minority disclosure. Furthermore, sexual minority disclosure was not a significant predictor of well-being. These findings indicate that bisexual disclosure is a distinct process from sexual minority disclosure for bisexual individuals, and it may be a more accurate indicator of bisexual individuals' well-being compared to their sexual minority disclosure. Past research reported similar findings when specifically examining outness to family: greater degrees of outness to family as bisexual predicted greater life satisfaction when controlling for outness to family as a sexual minority (Mohr et al., 2016). Findings from the present study expand upon this past literature in that they offer an analysis that is specific to disclosure and addressed a broader 
social sphere (i.e. looks at disclosure across social spheres instead of being specific to family).

It seems plausible that bisexual disclosure was found to be a positive predictor of well-being, whereas sexual minority disclosure was not, because bisexual disclosure offers bisexual individuals greater specificity (i.e. being identified as bisexual versus as a sexual minority) in their disclosure practices. Having this specificity when disclosing may result in bisexual individuals feeling greater authenticity, greater bisexual-specific social support/community and/or less internalized binegativity, compared to disclosing one's sexual minority identity, and consequently improve one's well-being. Furthermore, past research found that bisexual people reported more mental health concerns compared to LG people (Molina et al., 2015). Thus, it makes sense that alleviation of bisexual-specific stressors (e.g. limited bisexual disclosure) improves well-being and may account for the mental health disparities between these two populations. These results regarding bisexual disclosure further support the importance of considering bisexual disclosure and sexual minority disclosure as separate constructs when it comes to bisexual individuals' well-being.

Bisexual concealment was not a significant predictor of well-being when controlling for the statistically significant effect of sexual minority concealment. Perhaps this finding is related to the social context of bisexual concealment. By this I mean that bisexual concealment (e.g. not correcting others when they mistakenly identify you as gay/lesbian or straight, etc.) may overlap with aspects of bisexual erasure/invisibility (Barker, 2012). Some have suggested that the regularity of bisexual erasure/invisibility (e.g. the frequency through which bisexual people are not specifically acknowledged or misidentified as LG) creates 
labor for bisexual individuals because of having to assert their identity in order to avoid bisexual concealment (Rust, 2002). In response to bisexual erasure/invisibility, some bisexual individuals feel pressure to conceal their bisexuality, behaving as if one is gay or straight (Rust, 2002). Thus, it seems possible that some bisexual individuals may have learned to adapt to the negative impacts of erasure/invisibility and the pressures surrounding bisexual concealment in order to avoid becoming debilitated by the relentless occurrence of bisexual erasure/invisibility. In doing so, they can choose whether to partake in the labor of asserting their bisexual identities to others via decreasing their bisexual concealment. It may be through this adaptation in the face of bisexual erasure/invisibility that well-being remains unaffected by bisexual concealment. Thus, bisexual concealment may not be directly associated with less well-being. That is not to say that efforts to challenge bisexual erasure/invisibility or examination of indirect relationships between bisexual concealment and well-being should be dismissed or minimized (see Counseling and Social Justice Implications for further discussion of ways to advocate for bisexual visibility).

Given that bisexual concealment failed to predict well-being and was highly correlated with sexual minority concealment, these data imply that regardless of specificity (concealing one's general queerness or concealing one's bisexual identity), concealment did not relate to well-being when both types of concealment are included in the model. This finding conflicts with past LGB research that found concealment to have a stronger relationship with well-being compared to disclosure's relationship to well-being (Meidlinger \& Hope, 2014). It is important to keep in mind though that this past research did not differentiate bisexual people's outness as bisexual compared to their outness as a sexual 
minority in general. It is also valuable to recognize that disclosure occurs as an active indication of one's identity, whereas concealment occurs as an active avoidance of sharing one's identity (Meidlinger \& Hope, 2014). With disclosure representing an active indication of one's identity, gaining specificity in this realm of outness/disclosure (e.g. disclosing one's bisexual identity instead of just disclosing one's general sexual minority identity) was significantly related to well-being. Yet, with concealment representing avoidance of sharing one's identity, gaining specificity in the identity one is concealing did not have a connection to well-being. Phrased another way, it did not make a difference whether someone was concealing their bisexual identity or concealing their sexual minority identity in general, when both forms of concealment were considered, neither related to well-being.

Another plausible explanation for the finding that sexual minority concealment predicted well-being before adding bisexual concealment into the model is that bisexual people may have learned to adapt to bisexual concealment (as discussed two paragraphs above), but they have not adapted as well to sexual minority concealment. Perhaps there is something about bisexual people being mislabeled as straight/not-queer that is more deleterious than being mislabeled as queer but monosexual (e.g. gay/lesbian). Yet, when bisexual individuals self-report their experiences of bisexual concealment in addition to their experiences of sexual minority concealment, findings revealed that neither predicted wellbeing.

The possibility that more nuanced relationships (e.g. mediation and/or moderation) exist between bisexual concealment and well-being serves as another explanation for the lack of a direct relationship between these variables. Zane (2017), a bisexual writer and activist, 
explained that even though he used to decrease his bisexual concealment routinely by correcting people who misidentified him as gay, he does not correct others nearly as often now. Zane explained that after some time, the labor of correcting others "felt more like a chore" and he was "burning [himself] out by having the same conversation with new people multiple times a day." In time, Zane noticed that passing on the opportunity to correct others did not seem to affect him negatively. He believed that feeling more grounded in and being better able to self-affirm his bisexual identity allowed him to seek less validation and affirmation from those around him. This in turn, resulted in him feeling less affected by others' mislabeling of him and a decreased need to correct them.

Similarly, Dyar et al. (2015) suggested that the degree to which a bisexual individual integrates their bisexuality into their sense of self (via identity certainty, identity centrality, and/or positive identity valence) relates to one's concealment behavior and improves wellbeing. Paired with Zane's anecdote, Dyar et al.'s conclusion suggested that indirect processes (mediation and/or moderation) may exist between the constructs of bisexual concealment and well-being, such as one's experience of identity uncertainty, identity centrality, and positive identity valence. Understanding that bisexual concealment is not directly deleterious to wellbeing nor pathological may provide greater clarity regarding the role of bisexual concealment in the lives of bisexual people. This is particularly relevant given the lack of a statistically significant, direct relationship between bisexual concealment and well-being in the present study.

Of note, greater degrees of sexual minority concealment (e.g. not talking about same gender attractions) significantly predicted less well-being before considering the role of 
bisexual concealment in the model. This finding aligns with past research that revealed concealing same-sex sexual behavior had a deleterious effect on positive affect for behaviorally bisexual men (Schrimshaw et al., 2013). Yet for the present study, after including bisexual concealment, neither sexual minority concealment nor bisexual concealment were directly associated with well-being. This finding suggests that sexual minority concealment and bisexual concealment have shared variance when predicting wellbeing. The finding that neither surfaced as a direct predictor of well-being when both forms of concealment were examined suggests there may be indirect processes with concealment that influence well-being. For instance, prior research with a sample of behaviorally bisexual men captured that greater concealment of same-sex sexual behavior resulted in less general social support and greater internalized homophobia, which were detrimental to positive affect (Scrimshaw et al., 2013). Thus, additional consequences of sexual minority concealment and bisexual concealment, such as decreased social support, greater internalized homophobia, or greater internalized monosexism, that influence mental health outcomes warrant further investigation.

Another aim of the present study was to assess the role of authenticity as a mediator between bisexual disclosure and well-being and between bisexual concealment and wellbeing. Authenticity partially mediated the relationship between bisexual disclosure and wellbeing such that greater bisexual disclosure predicted greater authenticity, which then predicted greater well-being. Even with this mediation, the direct path from bisexual disclosure to well-being remained significant (i.e. greater bisexual disclosure predicted greater well-being). The mediation finding suggests bisexual individuals who disclose their 
bisexuality in ways that produce greater authenticity then experience greater well-being. As well, the significant direct effect between bisexual disclosure and well-being indicates that the path from bisexual disclosure to authenticity to well-being is not the sole process through which bisexual disclosure improves well-being. Thus, additional outcomes of bisexual disclosure that may improve well-being exist and were unexamined in the present study. Relational self-construal (i.e. an emphasis on connecting with others) is one such process for gay White men; verbal disclosure increased their intrinsic self-expression (akin to authenticity) and their relationship self-construal, both of which then increased well-being (Villicana et al., 2016). Consequently, inclusion of various processes that arise from disclosure (e.g. authenticity and relational self-construal) will assist in better understanding the array of processes through which bisexual disclosure is associated with well-being. Authenticity also mediated the relationship between bisexual concealment and wellbeing such that greater concealment predicted less authenticity, which in turn predicted less well-being. In this mediation, the direct effect of bisexual concealment on well-being was nonsignificant. Thus, these findings echo past research suggesting that concealment relates to authenticity in a detrimental way, and predicts reductions in well-being for LGB individuals (Sabat, Lindsey, \& King, 2014). However, the present study offers insight into this process specifically for bisexual individuals when concealing their bisexuality. Our findings reflect that specifically concealing one's bisexual identity, when controlling for concealing one's sexual minority identity, negatively predicts authenticity, which then impedes well-being. For example, it seems that bisexual concealment such as not correcting others when they mistakenly identify you as LG or straight (which can occur in LG contexts and 
straight/heterosexual contexts) thwarts authenticity. This expands upon previous research, such as that done by Sabat et al. (2014), because it demonstrates that sexual minority concealment is not the only form of concealment that lowers authenticity for bisexual individuals.

Of note, the nonsignificant findings for the direct effect of bisexual concealment on well-being and the total effect of the mediation have large standard errors. This may indicate there is some noise associated with the effect of bisexual concealment on well-being. Thus, this mediation finding should be interpreted with caution.

Past research showed that greater amounts of distal stressors, such as heterosexist discrimination, were detrimental to authenticity for LGB individuals (Szymanski et al., 2017). The present mediational findings extend the literature by showing bisexual-specific proximal stressors (bisexual disclosure and concealment) also influence authenticity. This is of particular importance given that bisexual individuals navigate bisexual disclosure and concealment when participating in both heterosexual/straight and gay/lesbian social spheres (Brewster \& Moradi, 2010; Mohr et al., 2016). When engaging in these settings, bisexual individuals may experience bisexual concealment lessening their authenticity and subsequently their well-being and/or bisexual disclosure increasing their authenticity and well-being.

Authenticity did not significantly moderate the relationship between bisexual disclosure and well-being nor between bisexual concealment and well-being. This nonsignificant moderation finding indicates that for bisexual people with higher levels of authenticity, the influence of their bisexual disclosure or concealment on their well-being 
remained essentially the same as that for bisexual people with lower levels of authenticity. In other words, having a lower level of authenticity did not negate the beneficial aspects of bisexual disclosure on well-being. It seems there may be something about bisexual disclosure that is a form of authenticity in and of itself. Minority stress theory (Meyer, 2003) predicted that identity characteristics moderate the relationship between proximal stressors and mental health outcomes. The present study findings did not parallel Meyer's theory; authenticity (as an identity characteristic) did not moderate the relationship between proximal stressors (bisexual disclosure and concealment) and well-being.

\section{Counseling and Social Justice Implications}

An array of implications come to light regarding the present findings. The finding that bisexual disclosure significantly predicted well-being above and beyond the ability of sexual minority disclosure to predict well-being, speaks to the unique role bisexual disclosure plays in the lives of bisexual individuals. Within the context of client goals, cultural influences, and timing/readiness, I encourage mental health professionals to consider the influence of bisexual clients' disclosure specifically as bisexual compared to their disclosure as a sexual minority, and how this may contribute to their client's well-being. This can be pursued through inquiring about bisexual clients' disclosure practices across these two identity domains (bisexual and sexual minority) and/or providing psychoeducation about the influence of each on well-being. Nonetheless, disclosure of either bisexual identity or sexual minority identity should be couched within a client's context and readiness factors, irrespective of disclosure's association with well-being. 
Furthermore, some mental health practitioners offer sexual minority or LGBTQfocused support groups. In response to the present finding, they may find it beneficial to offer bisexual-specific support groups. In doing so, they could provide bisexual clients with a space to experience greater bisexual disclosure and support with navigating bisexual disclosure outside of the support group. Graduate training programs can also take part in aiding mental health professionals to understand the different processes bisexual individuals face regarding disclosure. For instance, when discussing sexual minority identities in multicultural courses, faculty can emphasize that bisexual individuals navigate both disclosure as a sexual minority and disclosure as bisexual, how these processes are different from each other, and how they contribute to well-being.

The present finding also holds value when considering LGBTQ community events and celebrations. Two such celebrations are National Coming Out Day on October 11 and Bi Visibility Day on September 23. Having celebrations that are bisexual-specific and/or finding ways to tailor general LGBTQ celebrations for one's bisexual identity may prove useful in increasing bisexual individuals' well-being. As well, holding community events that offer bisexual individuals the chance for greater bisexual disclosure, such as bisexual-specific support groups and organizations, seem advantageous to bisexual individuals' well-being. Groups such as these can be offered through local LGBTQ community centers, LGBTQ nonprofit organizations, bisexual-specific non-profit organizations (e.g. PAVES in Colorado), and/or university LGBTQ programming. Mental health professionals can contribute to bisexual individuals' having greater opportunity for bisexual disclosure and increased wellbeing through supporting bisexual-specific support groups and organizations. 
Mediational findings in the present study elucidate a path from bisexual disclosure to authenticity to well-being, and a path from bisexual concealment to authenticity to wellbeing suggesting that disclosing one's bisexual identity or decreasing one's bisexual concealment in a manner that yields greater authenticity can result in greater well-being. These results call for interventions to aid bisexual individuals in achieving greater bisexual disclosure, less bisexual concealment, and greater authenticity, instead of focusing on just one part in the link to well-being. Specifically, it appears fruitful to explore with bisexual clients different ways they can achieve bisexual disclosure and avoid bisexual concealment, which in turn allows them to feel more authentic. Past findings, such as those from Villicana et al. (2016), that illuminated how verbal outness had different implications on well-being for gay White men than it did for gay Latino men should be considered in understanding the current findings. By this, I mean that interventions to assist bisexual individuals in reaching greater bisexual disclosure and/or less bisexual concealment may or may not include the bisexual person practicing greater verbal outness. I recommend that clinicians consider the range of outness approaches a bisexual client can use to share their identity. Clinicians should work with clients to utilize outness approaches that feel authentic for the client and align with the client's cultural values. Deconstructing the notion that greater bisexual outness (in regards to disclosure and concealment) directly results in greater well-being is worth exploring with bisexual clients and in bisexual community spaces.

The value of offering bisexual-specific support groups may be further increased by including authenticity-based writing exercises. Several authenticity-based narrative exercises have been studied, such as asking participants to write about a situation where they feel they 
can be their true selves (Turner \& Billings, 1991) or asking participants to reflect on past situations where they felt most and least true to themselves (Lenton, Bruder, Slabu, \& Sedikides, 2013). Writing about when one felt most like their true self (compared to least like their true self) was associated with various positive mental health constructs such as feelings of contentment, self-esteem, autonomy, and meaning (Lenton et al., 2013). These narrative exercises could be tailored to focus more specifically on one's bisexuality, such as asking clients to write about a situation where they feel they can be true to their bisexual identity or asking them to reflect on times they felt they were most true and least true to their bisexuality. Given past findings with authenticity narrative exercises (Lenton et al., 2013), bisexual-specific authenticity narrative exercises may also yield mental health benefits such as those reported by Lenton et al. (2013).

Advocacy work that assists in dismantling the assumption that bisexuality equals inauthenticity are vital. This can include efforts such as online campaigns which feature bisexual-affirming messages (e.g. use of \#BiInSci, \#thisiswhatbisexuallookslike, \#SomeBisArePoly \#SomeBisAreNot), challenging biphobic messages in both straight and gay/lesbian community spaces, and dismantling bisexual erasure/invisibility. Efforts such as these can help shift bisexual individuals from being the "invisible majority" or silenced majority to being properly acknowledged, supported, and empowered. Adding the construct of authenticity into the bisexual outness discourse, especially given the societal assumptions that bisexual individuals cannot be authentically living (Brewster \& Moradi, 2010), can provide a more expansive understanding of what health and well-being means for bisexual individuals. 


\section{Strengths, Limitations, and Future Research}

Several strengths are apparent in the present study. First, a multitude of bisexualspecific research studies illuminate experiences of discrimination and/or distress faced by bisexual individuals (Dyar et al., 2014, Lambe et al., 2017; Watson et al., 2016), yet few exist that focus on the positive psychology of bisexual individuals (Vaughan et al., 2014). The present study, given its focus on variables such as authenticity and well-being, is one of few bisexual-specific positive psychology studies. Bisexual individuals face an abundance of societal messages that declaring a bisexual identity is not an authentic way of being (e.g. bisexuality is an invalid or temporary identity; Brewster \& Moradi, 2010). Thus, examining the presence of authenticity that bisexual individuals achieve despite these societal messages, and the role of authenticity in bisexual individuals' well-being seems to be of importance.

Furthermore, findings from the present study extended the literature on minority stress theory for bisexual individuals. More precisely, one of the most salient strengths of the present study is attention to the differences in outness bisexual individuals face when considering their outness as a sexual minority and their outness specifically as bisexual (Mohr et al., 2016). Despite previous findings that bisexual outness to family predicted life satisfaction when controlling for sexual minority outness to family (Mohr et al., 2016), limited studies have continued to investigate the specific role of bisexual outness on mental health outcomes, when controlling for sexual minority outness. Accordingly, the present study considered Mohr et al.'s (2016) past finding, and found that bisexual disclosure positively predicted variance in well-being when controlling for sexual minority disclosure. This finding contributes to the study being noteworthy, yet it possessed a small effect size. 
Nonetheless, this study is not without its limitations. The findings are correlational and non-longitudinal; therefore causality cannot be assumed. As discussed by Barringer, Sumerau, and Gay (2017), disclosure has been viewed as both something that arises out of positive emotions and as something that may lead to positive emotions. In light of this reciprocal relationship between disclosure and positive emotions, it would seem that the disclosure-well-being relationship in the present study could also be reciprocal (i.e. increases in well-being may also predict greater disclosure). The present study's sample consisted of mostly Non-Hispanic, White participants and women (i.e. women, cisgender women, trans women). Previous reports detailed that the bisexual population in the United States is more racially diverse than both the heterosexual population and the population at large. Moreover, transgender individuals seem to make up the majority of the bisexual population (MAP, 2016). Thus, the obtained sample fails to capture some of the diversity within the bisexual population and has limitations in its generalizability to the U.S. bisexual population at large. Another methodological concern in the present study is the slight word modifications made to the LGB-PIM authenticity subscale. Changing wording in the items from "LGB" to "bisexual" to cue participants to more specifically consider their bisexual identity over their sexual minority identity may offer conceptual issues. One such change was the LGB-PIM authenticity item of "I feel I can be honest and share my LGBT identity with others" to "I feel I can be honest and share my bisexual identity with others." A bisexual person sharing their sexual identity with others is a different process than it is for LG individuals (Balsam \& Mohr, 2007). More specifically, bisexual people's feelings about being able to share their bisexual identity varies across LG, bisexual, and heterosexual/straight social spheres. 
Although the EFA confirmed loading of the adapted items into a single factor, having an authenticity scale specifically constructed to capture the unique experiences of achieving authenticity within one's bisexual identity is preferred (Moradi, Mohr, Worthington, \& Fassinger, 2009; Moradi, van den Berg, \& Epting, 2009). Finally, listwise deletion was employed for participants who were missing items or responded N/A to all items on the disclosure and concealment measures. However, a participant that responds with N/A to all outness items is conceptually different from a participant that does not respond to the items. The present findings do not offer insight into how participants responding with only N/A may differ from those included in the analyses regarding their experiences of outness, authenticity, and well-being.

In response to these limitations, multiple avenues of future research would be fruitful. Experimental, quasi-experimental, and longitudinal investigations focused on the variables of outness, authenticity, and well-being would be highly informative. Studies within these methodologies would allow for better understanding of the sequencing of these variables and the causal influence of authenticity on well-being. Echoing the implications from Riggle et al.'s (2017) findings that authenticity significantly, positively predicted well-being, assessing the effectiveness of authenticity-promoting interventions on sexual minority people's wellbeing is encouraged.

Minority stress theory detailed that minority stressors, such as concealment and disclosure, are distinct from general stress (Meyer, 2003). Including the variable of general stress into the present study's focus would help assess how general stress manifests for bisexual samples and if minority stressors such as bisexual disclosure and bisexual 
concealment are unique predictors of mental health outcomes when controlling for general stress. Continued examination of the adapted, bisexual-specific NOS used in the present study is encouraged. Further assessment of this instrument's psychometric properties with bisexual samples, such as the measure's factor structure, test-retest reliability and evidence for convergent validity, will offer greater evaluation of the scale's present adaptation for bisexual research. Lastly, more nuanced study of various bisexual disclosure tactics would expand our understanding of minority stress theory for bisexual individuals. Specifically examining the influence of verbal compared to non-verbal disclosure (e.g. Villicana et al., 2016) or the role of disclosure via appearance strategies such as clothing and style (e.g. Valentine, 2015) on authenticity and mental health outcomes for bisexual people of color samples would be informative. Such findings might assist in understanding the diversity of disclosure practices among bisexual individuals, and how these disclosure practices influence the well-being of bisexual people of color.

\section{Conclusions}

With bisexual individuals being the "invisible majority" of the sexual minority community (MAP, 2016), greater attention to their specific mental health needs is warranted. The present findings highlight the influence of bisexual disclosure and concealment, when controlling for sexual minority disclosure and concealment, on authenticity and well-being. It elucidates that disclosing one's bisexuality (i.e. sharing that one has attractions to more than one gender) increases well-being and that this type of disclosure affects well-being differently than disclosing one's sexual minority identity (i.e. sharing that one has samegender attractions). Yet, the same findings were not present for bisexual concealment. 
Furthermore, opportunities for both greater bisexual disclosure and less bisexual concealment should produce greater authenticity, which subsequently improves or is related to bisexual individuals' well-being. Mental health practitioners are encouraged to consider the influence bisexual-specific disclosure may have on bisexual clients' well-being. Training that orients practitioners to acknowledge distinctions between bisexual clients' outness (disclosure and concealment) as a sexual minority and their outness as bisexual is recommended. Assessing clients' bisexual disclosure and concealment practices in relation to increasing their authenticity may prove fruitful when working to improve bisexual clients' well-being. 


\section{REFERENCES}

Balsam, K. F. \& Mohr, J. J. (2007). Adaptation to sexual orientation stigma: A comparison of bisexual and lesbian/gay adults. Journal of Counseling Psychology, 54(3), 306-319. doi: 10.1037/0022-0167.54.3.306

Barker, M., Richards, C., Jones, R., Bowes-Catton, H., Plowman, T., Yockney, J., \& Morgan, M. (2012). The bisexuality report: Bisexual inclusion in LGBT equality and diversity. Retrieved from http://www.lgbt-equality.co.uk/wp-content/uploads/2016/02/TheBisexuality-Report.pdf

Barringer, M. N., Sumerau, J. E., \& Gay, D. A. (2017). Examining differences in identity disclosure between monosexuals and bisexuals. Sociological Spectrum, 37(5), 319333. doi: 10.1080/02732173.2017.1348276

BiNet USA (2015). Bisexual media guide marriage edition. Retrieved from http://www.binetusa.org/Downloads/BiNet_USA_Bisexual_Media_Guide_Marriage_ Equality_Edition.pdf

Birichi, D. K. (2015). Minority stress and well-being in adult gay men: The mediating role of authenticity (Doctoral dissertation). Open Access Dissertations, University of Miami, Miami, FL.

Brewster, M. E., \& Moradi, B. (2010). Perceived experiences of anti-bisexual prejudice: Instrument development and evaluation. Journal of Counseling Psychology, 57(4), 451-468. doi:10.1037/a0021116

Brewster, M. E., Moradi, B., DeBlaere, C., \& Velez, B. L. (2013). Navigating the 
borderlands: The roles of minority stressors, bicultural self-efficacy, and cognitive flexibility in the mental health of bisexual individuals. Journal of Counseling Psychology, 60(4), 543-556. doi:10.1037/a0033224

Brewster, M. E., Velez, B. L., Foster, A., Esposito, J., \& Robinson, M. A. (2016). Minority stress and the moderating role of religious coping among religious and spiritual sexual minority individuals. Journal of Counseling Psychology, 63(1), 119-126. doi:10.1037/cou0000121

Brownfield, J. M., Brown, C., Jeevanba, S. B., \& VanMattson, S. B. (2018). More than simply getting bi: Coming out growth for bisexual individuals. Psychology of Sexual Orientation and Gender Diversity, 5(2), 220-232. doi: 10.1037/sgd0000282

Cohen, J. (1992). A power primer. Psychological Bulletin, 112, 155-159. http://dx.doi.org/10.1037/0033-2909.112.1.155

Critcher, C. R., \& Ferguson, M. J. (2014). The cost of keeping it hidden: Decomposing concealment reveals what makes it depleting. Journal of Experimental Psychology: General, 143(2), 721-735. doi:10.1037/a0033468

Dyar, C., Feinstein, B. A., \& London, B. (2014). Dimensions of sexual identity and minority stress among bisexual women: The role of partner gender. Psychology of Sexual Orientation and Gender Diversity, 1(4), 441-451. doi: 10.1037/sgd0000063

Dyar, C., Feinstein, B. A., \& London, B. (2015). Mediators of differences between lesbians and bisexual women in sexual identity and minority stress. Psychology of Sexual Orientation and Gender Diversity, 2(1), 43-51.

Eisner, S. (2013). Bi: Notes for a bisexual revolution. Berkley, CA: Seal Press. 
Flanders, C. E., LeBreton, M. E., Robinson, M., Bian, J., \& Caravaca-Morera, J. A. (2017). Defining bisexuality: Young bisexual and pansexual people's voices. Journal of Bisexuality, 17(1), 39-57.

Frazier, P. A., Tix, A. P., \& Barron, K. E. (2004). Testing moderator and mediator effects in counseling psychology research. Journal of Counseling Psychology, 51(1), 115-134.

Galupo, M. P., Mitchell, R. C., \& Davis, K. S. (2015). Sexual minority self-identification: Multiple identities and complexity. Psychology Of Sexual Orientation and Gender Diversity, 2(4), 355-364. doi:10.1037/sgd000013

Gelso, C., Nutt Williams, E. \& Fretz, B R., (2014). Counseling psychology, ${ }^{\text {rd }}$ Ed. Washington DC: American Psychological Association.

Hayes, A. (2013). Introduction to mediation, moderation, and conditional process analysis, ${ }^{\text {st }}$ Ed. New York, NY: The Guilford Press.

Herek, G. M., Norton, A. T., Allen, T. J., \& Sims, C. L. (2010). Demographic, psychological, and social characteristics of self-identified lesbian, gay, and bisexual adults in a US probability sample. Sexuality Research and Social Policy, 7(3), 176-200.

Jackson, S. D., \& Mohr, J. J. (2016). Conceptualizing the closet: Differentiating stigma concealment and nondisclosure processes. Psychology of Sexual Orientation and Gender Diversity, 3(1), 80-92.

Jorm, A. F., Korten, A. E., Rodgers, B., Jacomb, P. A., \& Christensen, H. (2002). Sexual orientation and mental health: Results from a community survey of young and middle-aged adults. The British Journal of Psychiatry, 180(5), 423-427.

Kline, R. B. (2011). Principles and practice of structural equation modeling. New York, NY: The Guilford Press. 
Lambe, J., Cerezo, A., \& O'Shaughnessy, T. (2017). Minority stress, community involvement, and mental health among bisexual women. Psychology of Sexual Orientation and Gender Diversity, 4(2), 218-226.

Lazarus, R. S., \& Folkman, S. (1984). Stress, appraisal, and coping. New York: Springer.

Lehavot, K., \& Simoni, J. M. (2011). The impact of minority stress on mental health and substance use among sexual minority women. Journal of Consulting and Clinical Psychology, 79, 159-170. http://dx.doi.org/ 10.1037/a0022839

Lenton, A.P., Bruder, M., Slabu, L., \& Sedikides, C. (2013). How does “Being real” feel? The experience of state authenticity. Journal of Personality, 81(3), 276-289.

Levitt, H. M., Horne, S. G., Herbitter, C., Ippolito, M., Reeves, T., Baggett, L. R., \& ... Geiss, M. (2016). Resilience in the face of sexual minority stress: 'Choices' between authenticity and self-determination. Journal of Gay \& Lesbian Social Services: The Quarterly Journal of Community \& Clinical Practice, 28(1), 67-91. doi:10.1080/10538720.2016.1126212

Lick, D. J., Durso, L. E., \& Johnson, K. L. (2013). Minority stress and physical health among sexual minorities. Perspectives on Psychological Science, 8(5), 521-548.

Meidlinger, P. C., \& Hope, D. A. (2014). Differentiating disclosure and concealment in measurement of outness for sexual minorities: The Nebraska Outness Scale. Psychology of Sexual Orientation and Gender Diversity, 1(4), 489-497.

Mereish, E. H., Katz-Wise, S. L., \& Woulfe, J. (2017). Bisexual-specific minority stressors, psychological distress, and suicidality in bisexual individuals: The mediating role of loneliness. Prevention Science, 1-10. 
Meyer, I. H. (1995). Minority stress and mental health in gay men. Journal of Health and Social Behavior, 36, 38-56.

Meyer, I. H. (2003). Prejudice, social stress, and mental health in lesbian, gay, and bisexual populations: Conceptual issues and research evidence. Psychological Bulletin, 129(5), 674-697. doi:10.1037/0033-2909.129.5.674

Miller, M., André, A., Ebin, J., \& Bessonova, L. (2007). Bisexual health: An introduction and model practices for HIV/STI prevention programming. New York: National Gay and Lesbian Task Force Policy Institute, the Fenway Institute at Fenway Community Health, and BiNet USA.

Mitchell, R. C., Davis, K. S., \& Galupo, M. P. (2015). Comparing perceived experiences of prejudice among self-identified plurisexual individuals. Psychology \& Sexuality, 6(3), $245-257$.

Mohr, J., \& Fassinger, R. (2000). Measuring dimensions of lesbian and gay male experience. Measurement and Evaluation in Counseling and Development, 33(2), 66-90.

Mohr, J. J., Jackson, S. D., \& Sheets, R. L. (2016). Sexual orientation self-presentation among bisexual-identified women and men: Patterns and predictors. Archives of Sexual Behavior, 1-15.

Molina, Y., Marquez, J. H., Logan, D. E., Leeson, C. J., Balsam, K. F., \& Kaysen, D. L. (2015). Current intimate relationship status, depression, and alcohol use among bisexual women: The mediating roles of bisexual-specific minority stressors. Sex Roles, 73(1-2), 43-57. 
Monro, S., Hines, S., \& Osborne, A. (2017). Is bisexuality invisible? A review of sexualities scholarship 1970-2015. The Sociological Review, 65(4), 663-681. doi: $10.1177 / 0038026117695488$.

Moradi, B., Mohr, J. J., Worthington, R. L., \& Fassinger, R. E. (2009). Counseling psychology research on sexual (orientation) minority issues: Conceptual and methodological challenges and opportunities. Journal Of Counseling Psychology, 56(1), 5-22. doi:10.1037/a0014572

Moradi, B., van den Berg, J. J., \& Epting, F. R. (2009). Threat and guilt aspects of internalized antilesbian and gay prejudice: An application of personal construct theory. Journal Of Counseling Psychology, 56(1), 119-131. doi:10.1037/a0014571

Morris, J. F., Waldo, C. R., \& Rothblum, E. D. (2001). A model of predictors and outcomes of outness among lesbian and bisexual women. American Journal of Orthopsychiatry, 71, 61-71. doi:10.1037/0002-9432.71.1.61

Movement Advancement Project (2016). Invisible majority: The disparities facing bisexual people and how to remedy them. Retrieved from: http://www.lgbtmap.org/policy-andissue-analysis/invisible-majority.

O'Connor, J. (2016). Outness, self-esteem, stigma, psychological health and mobile dating application use in gay and bisexual men. Unpublished manuscript, Department of Psychology, Dublin Business School, Dublin, Ireland. Retrieved from http://hdl.handle.net/10788/3121

Ochs, R. Bisexual resources. Retrieved from https://robynochs.com/bisexual/ Pascale-Hague, D. (2015). Exploring bisexual-identified persons experiences of belonging. 
(Doctoral dissertation). Theses and Dissertations-Educational, School, and Counseling Psychology, University of Kentucky, Lexington, KY.

Paul, R., Smith, N. G., Mohr, J. J., \& Ross, L. E. (2014). Measuring dimensions of bisexual identity: Initial development of the Bisexual Identity Inventory. Psychology Of Sexual Orientation And Gender Diversity, 1(4), 452-460. doi:10.1037/sgd0000069

Persson, T. J., \& Pfaus, J. G. (2015). Bisexuality and mental health: Future research directions. Journal of Bisexuality, 15(1), 82-98.

Ragins, B. R., \& Cornwell, J. M. (2001). Pink triangles: Antecedents and consequences of perceived workplace discrimination against gay and lesbian employees. Journal of Applied Psychology, 86(6), 1244-1261.

Riggle, E. D., Mohr, J. J., Rostosky, S. S., Fingerhut, A. W., \& Balsam, K. F. (2014). A multifactor Lesbian, Gay, and Bisexual Positive Identity Measure (LGB-PIM). Psychology of Sexual Orientation and Gender Diversity, 1(4), 398-411.

Riggle, E. D., Rostosky, S. S., Black, W. W., \& Rosenkrantz, D. E. (2017). Outness, concealment, and authenticity: Associations with LGB individuals’ psychological distress and well-being. Psychology of Sexual Orientation and Gender Diversity, $4(1), 54-62$.

Riggle, E. B., Whitman, J. S., Olson, A., Rostosky, S. S., \& Strong, S. (2008). The positive aspects of being a lesbian or gay man. Professional Psychology: Research and Practice, 39(2), 210-217. doi:10.1037/0735-7028.39.2.210 
Roberts, T. S., Horne, S. G., \& Hoyt, W. T. (2015). Between a gay and a straight place: Bisexual individuals' experiences with monosexism. Journal of Bisexuality, 15(4), 554-569.

Rust, P. C. R. (2002). Bisexuality: The state of the union. Annual Review of Sex Research, $13,180-240$.

Ryff, C. D. (1989). Happiness is everything, or is it? Explorations on the meaning of psychological well-being. Journal of Personality and Social Psychology, 57(6), 10691081.

Sabat, I., Lindsey, A., \& King, E. (2014). Antecedents, outcomes, prevention and coping strategies for lesbian, gay, and bisexual workplace stress. In C. C. Rosen, J. R. B. Halbesleben, \& P. L. Perrewé (Eds.), The role of demographics in occupational stress and well being (pp. 173-198). Bingley, UK: Emerald Group Publishing Limited.

Scales Rostosky, S., Riggle, E. D., Pascale-Hague, D., \& McCants, L. E. (2010). The positive aspects of a bisexual self-identification. Psychology \& Sexuality, 1(2), 131-144.

Schrimshaw, E. W., Siegel, K., Downing Jr, M. J., \& Parsons, J. T. (2013). Disclosure and concealment of sexual orientation and the mental health of non-gay-identified, behaviorally bisexual men. Journal of Consulting and Clinical Psychology, 81(1), 141-153.

Seligman, M. E. P. \& Csikszentmihalyi, M. (2000). Positive psychology: An introduction. American Psychologist, 55(1), 5-14. doi: 10.1037//0003-066X.55.1.5 
Selvidge, M. M. D., Matthews, C. R., \& Bridges, S. K. (2008). The relationship of minority stress and flexible coping to psychological well being in lesbian and bisexual women. Journal of Homosexuality, 55(3), 450-470. doi: 10.1080/00918360802345255

Selye, H. (1982). Stress and holistic medicine. In D. S. Sutterley \& G. F. Donnelly (Eds.), Coping with stress: A nursing perspective (pp. 69-72). Rockville, MD: Aspen Systems.

Smart, L., \& Wegner, D. M. (2000). The hidden costs of stigma. In T. F. Heatherton, R. E. Kleck, M. R. Hebl, \& J. G. Hull (eds.), The social psychology of stigma (pp. 220242). New York: Guilford Press.

Szymanski, D. M., Mikorski, R., \& Carretta, R. F. (2017). Heterosexism and LGB positive identity: Roles of coping and personal growth initiative. The Counseling Psychologist, 45(2), 294-319. doi:10.1177/0011000017697195

Tabachnick, B. G., \& Fidell, L. S. (2014). Using multivariate statistics, $6^{\text {th }}$ Edition. London: Pearson.

Thoits, P. (1999). Self, identitiy, stress, and mental health. In C. S. Aneshensel \& J. C. Phelan (Eds.), Handbook of sociology of mental health (pp. 345-368). New York: Kluwer Academic/Plenum.

Turner, R., \& Billings, V. (1991). The social context of self-feeling. In J. Howard \& P. Callero (Eds.), The self-society dynamic: Cognition, emotion, and action (pp. 103122). New York: Cambridge University Press.

Valentine, B. A. (2015). 'Daring to be ourselves': Explorations of authenticity, compassion, and discrimination for lesbian, gay, bisexual, and queer people of color (Doctoral 
dissertation). Open Access Dissertations, The University of Michigan, Ann Arbor, MI.

Vaughan, M. D., Miles, J., Parent, M. C., Lee, H. S., Tilgham, J. D., \& Prokhorets, S. (2014). A content analysis of LGBT-themed positive psychology articles. Psychology of Sexual Orientation and Gender Diversity, 1(4), 313-324. doi:10.1037/sgd0000060

Velez, B. L., \& Moradi, B. (2016). A moderated mediation test of minority stress: The role of collective action. The Counseling Psychologist, 44(8), 1132-1157.

Villicana, A. J., Delucio, K., \& Biernat, M. (2016). “Coming out” among gay Latino and gay White men: Implications of verbal disclosure for well-being. Self and Identity, 15(4), 468-487.

Watson, L. B., Velez, B. L., Brownfield, J., \& Flores, M. J. (2016). Minority stress and bisexual women's disordered eating: The role of maladaptive coping. The Counseling Psychologist, 44(8), 1158-1186. doi:10.1177/0011000016669233

Zane, Z. (2017, September 4). Good bi love: Why I don't correct every time someone mislabels my (bi)sexuality [Blog post]. Retrieved from https://bisexual.org/good-bilove-why-i-dont-correct-every-time-someone-mislabels-my-bisexuality/ 
Table 1.

Correlations, Reliability Coefficients, and Descriptives

\begin{tabular}{|c|c|c|c|c|c|c|}
\hline Variable & 1 & 2 & 3 & 4 & 5 & 6 \\
\hline 1. Sexual Minority Disclosure ${ }^{\mathrm{a}}$ & -- & & & & & \\
\hline 2. Sexual Minority Concealment ${ }^{\mathrm{a}}$ & $-.55^{*}$ & -- & & & & \\
\hline 3. Bisexual Disclosure ${ }^{a}$ & $.85^{*}$ & $-.50 *$ & -- & & & \\
\hline 4. Bisexual Concealment ${ }^{\mathrm{a}}$ & $-.48 *$ & $.82 *$ & $-.53 *$ & -- & & \\
\hline 5. Authenticity ${ }^{\mathrm{a}}$ & $.47 *$ & $-.44 *$ & $.52 *$ & $-.50 *$ & -- & \\
\hline 6. Well-Being ${ }^{\mathrm{a}}$ & $.18 *$ & $-.19 *$ & $.24 *$ & $-.20 *$ & $.29 *$ & -- \\
\hline 7. Some HS or HS Degree ${ }^{b}$ & -.03 & .01 & -.03 & -.02 & -.03 & $-.28 * *$ \\
\hline $\begin{array}{l}\text { 8. Some College or Assoc. } \\
\text { Degree }^{\mathrm{b}}\end{array}$ & -.05 & -.04 & -.07 & -.04 & .04 & $-.22 * *$ \\
\hline 9. Graduate Degree ${ }^{b}$ & .09 & -.04 & .06 & -.04 & -.01 & $.26 * *$ \\
\hline 10. Age $^{\mathrm{b}}$ & .01 & -.08 & .06 & -.04 & .09 & $.25 * *$ \\
\hline Reliability & .86 & .86 & .83 & .85 & .87 & .95 \\
\hline$M$ & 5.12 & 4.32 & 4.64 & 4.50 & 5.34 & 4.26 \\
\hline$S D$ & 2.37 & 2.50 & 2.20 & 2.49 & 1.21 & .80 \\
\hline Sample Range & $0-9.57$ & $0-10$ & $0-9.71$ & $0-10$ & $1.20-7$ & $1.79-5.86$ \\
\hline Possible Range & $0-10$ & $0-10$ & $0-10$ & $0-10$ & $1-7$ & $1-6$ \\
\hline
\end{tabular}

${ }^{\mathrm{a}} N=450 .{ }^{\mathrm{b}} N=447$ because three participants were missing educational level and age data. $* p<.01, * * p<.001$. 
Table 2.

Hierarchical Multiple Regression Analysis Predicting PWBS $(N=450)$

\begin{tabular}{|c|c|c|c|c|c|c|c|}
\hline & Step and variable & $B[S E]$ & $\mathrm{B}$ & $t$ & $p$ & $R^{2}$ & $\begin{array}{c}\text { Adjusted } \\
R^{2}\end{array}$ \\
\hline \multirow[t]{3}{*}{ Step 1} & & & & & & .042 & .038 \\
\hline & SM Disclosure & $.036[.019]$ & .105 & 1.896 & .059 & & \\
\hline & SM Concealment & $-.041[.018]$ & -.128 & -2.304 & .022 & & \\
\hline \multirow[t]{5}{*}{ Step 2} & & & & & & .068 & .060 \\
\hline & SM Disclosure & $-.041[.031]$ & -.120 & -1.305 & .193 & & \\
\hline & SM Concealment & $-.018[.027]$ & -.056 & -.658 & .511 & & \\
\hline & Bi Disclosure ${ }^{a}$ & $.099[.033]$ & .270 & 2.979 & .003 & & \\
\hline & Bi Concealment ${ }^{\mathrm{a}}$ & $-.024[.027]$ & -.074 & -.893 & .373 & & \\
\hline \multirow[t]{6}{*}{ Step 3} & & & & & & .100 & .090 \\
\hline & SM Disclosure & $-.046[.031]$ & -.134 & -1.484 & .138 & & \\
\hline & SM Concealment & $-.018[.027]$ & -.058 & -.687 & .492 & & \\
\hline & Bi Disclosure ${ }^{a}$ & $.075[.033]$ & .204 & 2.251 & .025 & & \\
\hline & Bi Concealment ${ }^{\mathrm{a}}$ & $-.022[.027]$ & -.005 & -.060 & .952 & & \\
\hline & Authenticity ${ }^{a}$ & $.146[.037]$ & .220 & 3.967 & .000 & & \\
\hline \multirow[t]{8}{*}{ Step 4} & & & & & & .102 & .088 \\
\hline & SM Disclosure & $-.047[.031]$ & -.138 & -1.520 & .129 & & \\
\hline & SM Concealment & $-.020[.027]$ & -.064 & -.756 & .450 & & \\
\hline & Bi Disclosure ${ }^{a}$ & $.077[.033]$ & .210 & 2.305 & .022 & & \\
\hline & Bi Concealment ${ }^{\mathrm{a}}$ & $.000[.027]$ & .000 & -.003 & .997 & & \\
\hline & Authenticity ${ }^{a}$ & $.138[.038]$ & .208 & 3.643 & .000 & & \\
\hline & Bi Disclosure X Authenticity & $-.005[.016]$ & -.019 & -.335 & .738 & & \\
\hline & Bi Concealment X Authenticity & $.007[.013]$ & .030 & .542 & .588 & & \\
\hline
\end{tabular}

Note PWBS = Psychological Well-Being Scale; SM Disclosure $=$ Nonheterosexual Disclosure; SM Concealment $=$ Nonheterosexual Concealment; Bi Disclosure $=$ Bisexual Disclosure; Bi Concealment $=$ Bisexual Concealment; ${ }^{a}$ Variable was mean centered. 


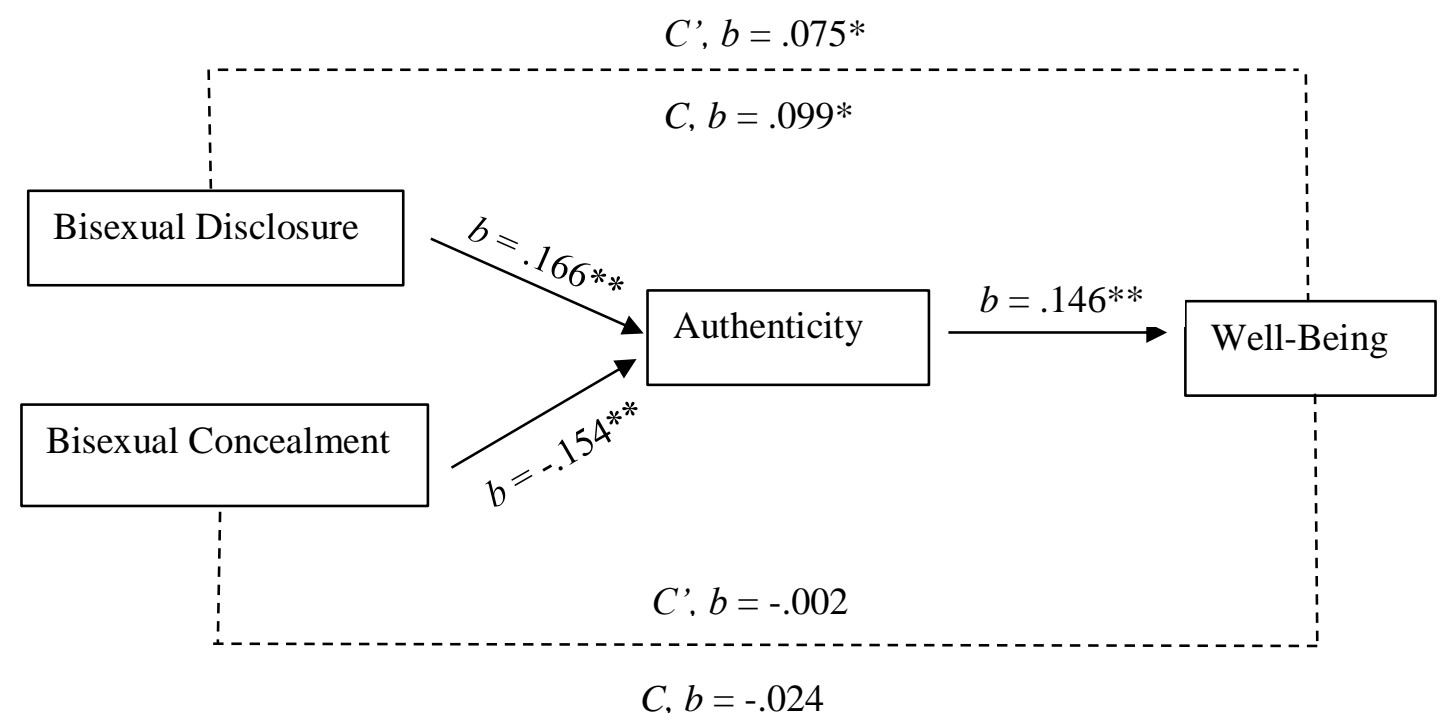

Note. $* p<.05, * * p<.001$.

Figure 1. Mediational diagram for hypotheses 2 and 5. 


\section{Appendix A}

\section{Minority Stress Model (Meyer, 2003)}

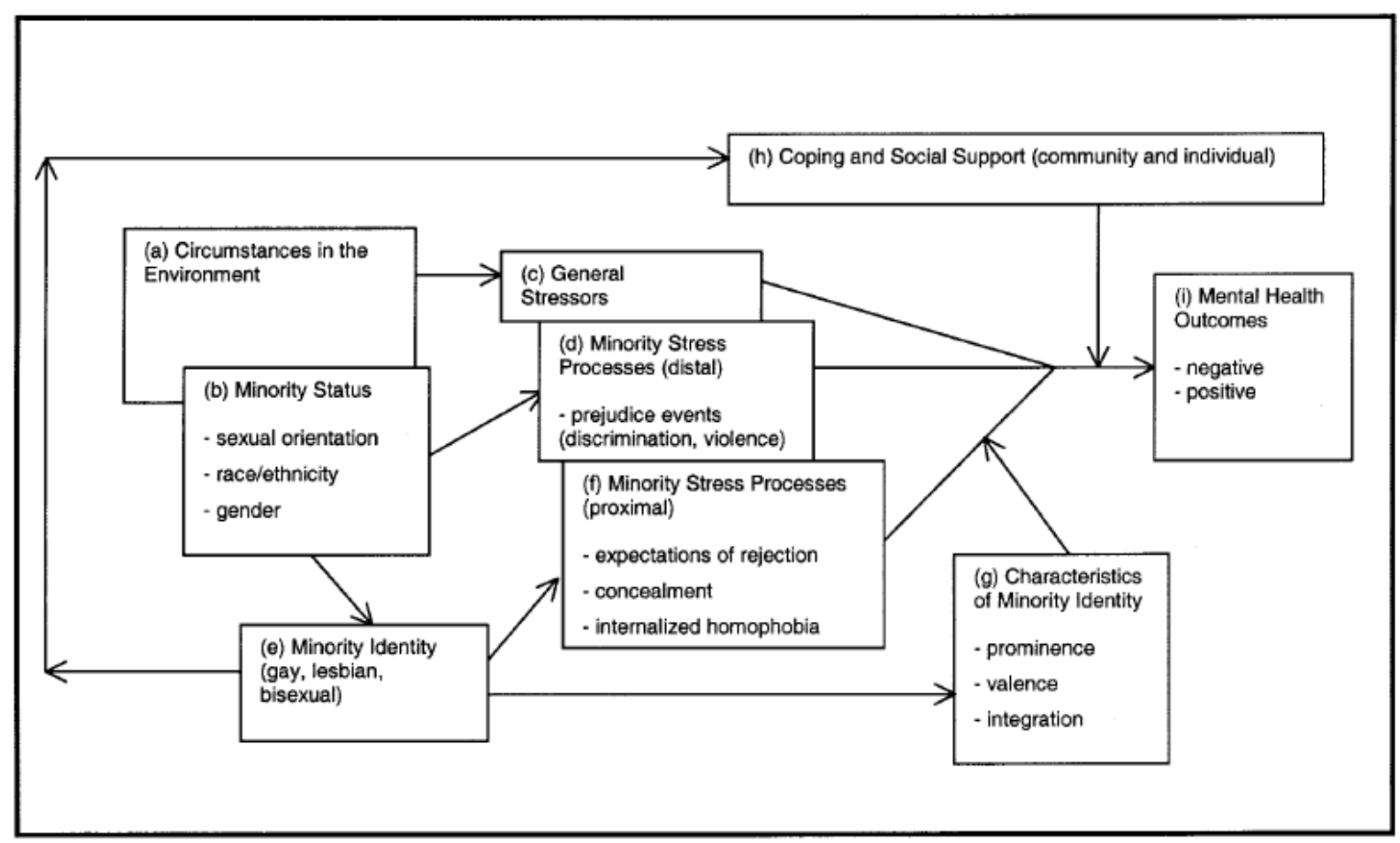

Figure 1. Minority stress processes in lesbian, gay, and bisexual populations. 


\section{Appendix B}

\section{Demographics Form}

1. Age in Years:

2. Please use your own words to describe your gender:

3. Please use your own words to describe your sexual identity (if you feel that the term bisexual does not fully encompass your sexual identity).

4. How out do you feel you are?

\begin{tabular}{|l|l|l|l|l|l|l|l|l|l|l|l|}
\hline & $\begin{array}{l}0 \% \\
\text { Not } \\
\text { at } \\
\text { all }\end{array}$ & $10 \%$ & $20 \%$ & $30 \%$ & $40 \%$ & $50 \%$ & $60 \%$ & $70 \%$ & $80 \%$ & $90 \%$ & $100 \%$ \\
Completely
\end{tabular}

5. Please indicate your highest level of education achieved:
a. Some High School/No Diploma
b. High School Diploma
c. GED
d. Vocational or Trade School
e. Some College/No Degree
f. Associates Degree
g. Bachelor's Degree (Ex: BA, BS, BSW)
h. Master's Degree (Ex: MA, MS, MSW, M.Ed)
i. Doctorate Degree (Ex: Ph.D., Ed.D., Sc.D., DSW, MD)
j. Specialist Degree (ex: Ed.S.)

6. Please identify your race/ethnicity/cultural identity:
a. Asian/Pacific Islander (e.g. East Asian, Southeast Asian, etc.)
b. Black/African American
c. Non-Hispanic Caucasian/White/European American
e. Hispanic/Latino/Latina/Latin@/LatinX
f. Middle Eastern 
g. Multiracial/ethnic

h. Native American/American Indian, please specify tribe:

i. If the above terms do not adequately describe your cultural identity, please do so in your own words:

7. Do you have international residency? If yes, how long have you resided in the United States?

8. Please indicate your spiritual/religious affiliation (if applicable):
a. Agnostic
b. Atheist
c. Buddist/Taoist
d. Christian/Catholic
e. Christian/Protestant
f. Christian/Other
g. Hindu
h. Jewish
i. Muslim/Islam
j. Spiritual, but not religious
k. Wiccan/Pagan/Neo-Pagan, please specify:
1. If not captured by the above options please use your own words to describe your identity:

9. Do you have a chronic illness or disability? (yes) or (no). If yes, please specify below:

10. Please identify your Personal Annual Income:
a. $0-9,999$
b. $10,000-19,999$
c. $20,000-29,999$
d. $30,000-39,999$
e. $40,000-49,999$
f. $50,000-59,999$
g. $60,000-69,999$
h. $70,000-79,999$
i. $80,000-89,999$
j. $90,000-99,999$
k. 100,000 or more

11. For the past six months please indicate in which area of the United States you live:

a. Northeast 

b. Southeast
c. Northwest
d. Midwest
e. Southwest
f. West Coast
g. Hawaii/Alaska

12. Please indicate your relationship status:
a. Single
b. In a monogamous relationship (i.e. dating only one person)
c. In a non-monogamous dating relationship (i.e. dating more than one person)
d. Polyamorous
e. Partnered
f. Married
g. Married/Partnered, but separated
h. Divorced
i. Widowed

13. Please indicate your current partner(s) gender (if applicable):
a. Man, not transgender
b. Woman, not transgender
c. Man of transgender experience (Trans man, transsexual man, FtM)
d. Woman of transgender experience (Trans woman, transsexual woman, MtF)
e. Genderqueer
f. If the above terms do not adequately describe your partner's gender, please use your own words to do so:

14. Please indicate your current partner(s) sexual identity (if applicable):
a. Heterosexual
b. Lesbian
c. Gay
d. Bisexual
e. Queer
f. Questioning
f. Pan/Omni-sexual
g. If not captured above please use your own words to describe: 


\section{Appendix C}

\section{Nebraska Outness Scale (Meidlinger \& Hope, 2014)}

\section{Nonheterosexual version}

\begin{tabular}{|c|c|c|c|c|c|c|c|c|c|c|c|c|}
\hline \multicolumn{13}{|c|}{$\begin{array}{l}\text { (NOS-D) What percent of people in this group do you think are aware of your sexual minority identity (meaning they } \\
\text { are aware that you consider yourself a sexual minority, not straight)? }\end{array}$} \\
\hline & $0 \%$ & $10 \%$ & $20 \%$ & $30 \%$ & $40 \%$ & $50 \%$ & $60 \%$ & $70 \%$ & $80 \%$ & $90 \%$ & $100 \%$ & N/A \\
\hline $\begin{array}{l}\text { Members of your } \\
\text { immediate family (e.g. } \\
\text { parents and siblings) }\end{array}$ & & & & & & & & & & & & \\
\hline $\begin{array}{l}\text { Members of your } \\
\text { extended family (e.g. } \\
\text { aunts, uncles, } \\
\text { grandparents, cousins) }\end{array}$ & & & & & & & & & & & & \\
\hline $\begin{array}{l}\text { Heterosexual/Straight } \\
\text { people you socialize } \\
\text { with (e.g. friends and } \\
\text { acquaintances) }\end{array}$ & & & & & & & & & & & & \\
\hline $\begin{array}{l}\text { Gay/Lesbian people you } \\
\text { socialize with (e.g. } \\
\text { friends and } \\
\text { acquaintances) }\end{array}$ & & & & & & & & & & & & \\
\hline $\begin{array}{l}\text { Bisexual people you } \\
\text { socialize with (e.g. } \\
\text { friends and } \\
\text { acquaintances) }\end{array}$ & & & & & & & & & & & & \\
\hline $\begin{array}{l}\text { People at your } \\
\text { work/school (e.g. } \\
\text { coworkers, supervisors, } \\
\text { instructors, students) } \\
\end{array}$ & & & & & & & & & & & & \\
\hline $\begin{array}{l}\text { Strangers (e.g. someone } \\
\text { you have a causal } \\
\text { conversation with in } \\
\text { line at the store) }\end{array}$ & & & & & & & & & & & & \\
\hline
\end{tabular}

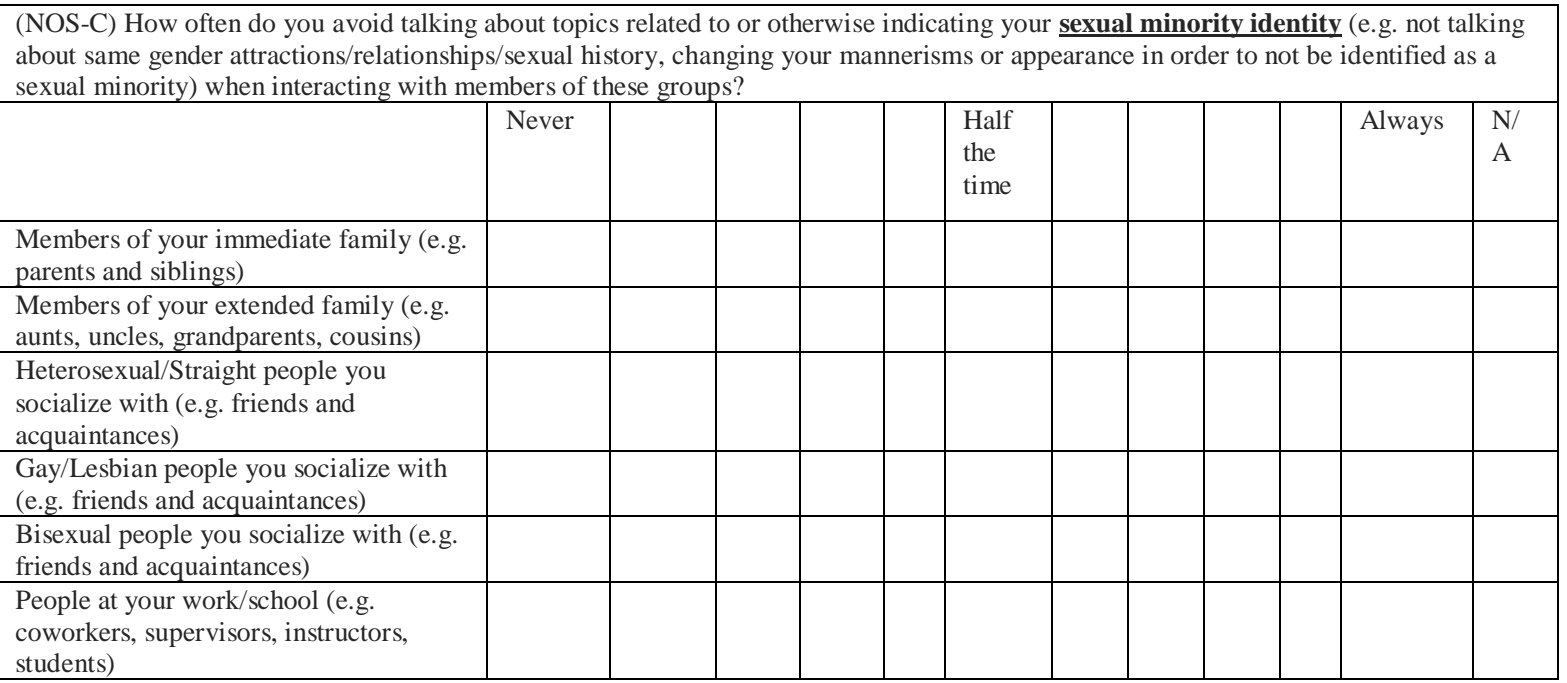




\begin{tabular}{|l|l|l|l|l|l|l|l|l|l|l|}
\hline $\begin{array}{l}\text { Strangers (e.g. someone you have a } \\
\text { causal conversation with in line at the } \\
\text { store) }\end{array}$ & & & & & & & & & & \\
\hline
\end{tabular}

\section{Bisexual version}

\begin{tabular}{|c|c|c|c|c|c|c|c|c|c|c|c|c|}
\hline & $0 \%$ & $10 \%$ & $20 \%$ & $30 \%$ & $40 \%$ & $50 \%$ & $60 \%$ & $70 \%$ & $80 \%$ & $90 \%$ & $100 \%$ & N/A \\
\hline $\begin{array}{l}\text { Members of your } \\
\text { immediate family (e.g. } \\
\text { parents and siblings) }\end{array}$ & & & & & & & & & & & & \\
\hline $\begin{array}{l}\text { Members of your } \\
\text { extended family (e.g. } \\
\text { aunts, uncles, } \\
\text { grandparents, cousins) }\end{array}$ & & & & & & & & & & & & \\
\hline $\begin{array}{l}\text { Heterosexual/Straight } \\
\text { people you socialize } \\
\text { with (e.g. friends and } \\
\text { acquaintances) }\end{array}$ & & & & & & & & & & & & \\
\hline $\begin{array}{l}\text { Gay/Lesbian people you } \\
\text { socialize with (e.g. } \\
\text { friends and } \\
\text { acquaintances) }\end{array}$ & & & & & & & & & & & & \\
\hline $\begin{array}{l}\text { Bisexual people you } \\
\text { socialize with (e.g. } \\
\text { friends and } \\
\text { acquaintances) }\end{array}$ & & & & & & & & & & & & \\
\hline $\begin{array}{l}\text { People at your } \\
\text { work/school (e.g. } \\
\text { coworkers, supervisors, } \\
\text { instructors, students) } \\
\end{array}$ & & & & & & & & & & & & \\
\hline $\begin{array}{l}\text { Strangers (e.g. someone } \\
\text { you have a causal } \\
\text { conversation with in } \\
\text { line at the store) }\end{array}$ & & & & & & & & & & & & \\
\hline
\end{tabular}

(NOS-C) How often do you avoid talking about topics related to or otherwise indicating your bisexual identity (e.g. avoid using the label bisexual and/or using terms other than bisexual to describe yourself when not feeling comfortable or safe to use a bisexual label, avoid using pronouns that would reveal a partner/significant other's gender, avoid disclosing attractions/relationship history/sexual history that reveals these instances occurring across genders, not correcting others when they mistakenly identify you as gay/lesbian or straight) when interacting with members of these groups?

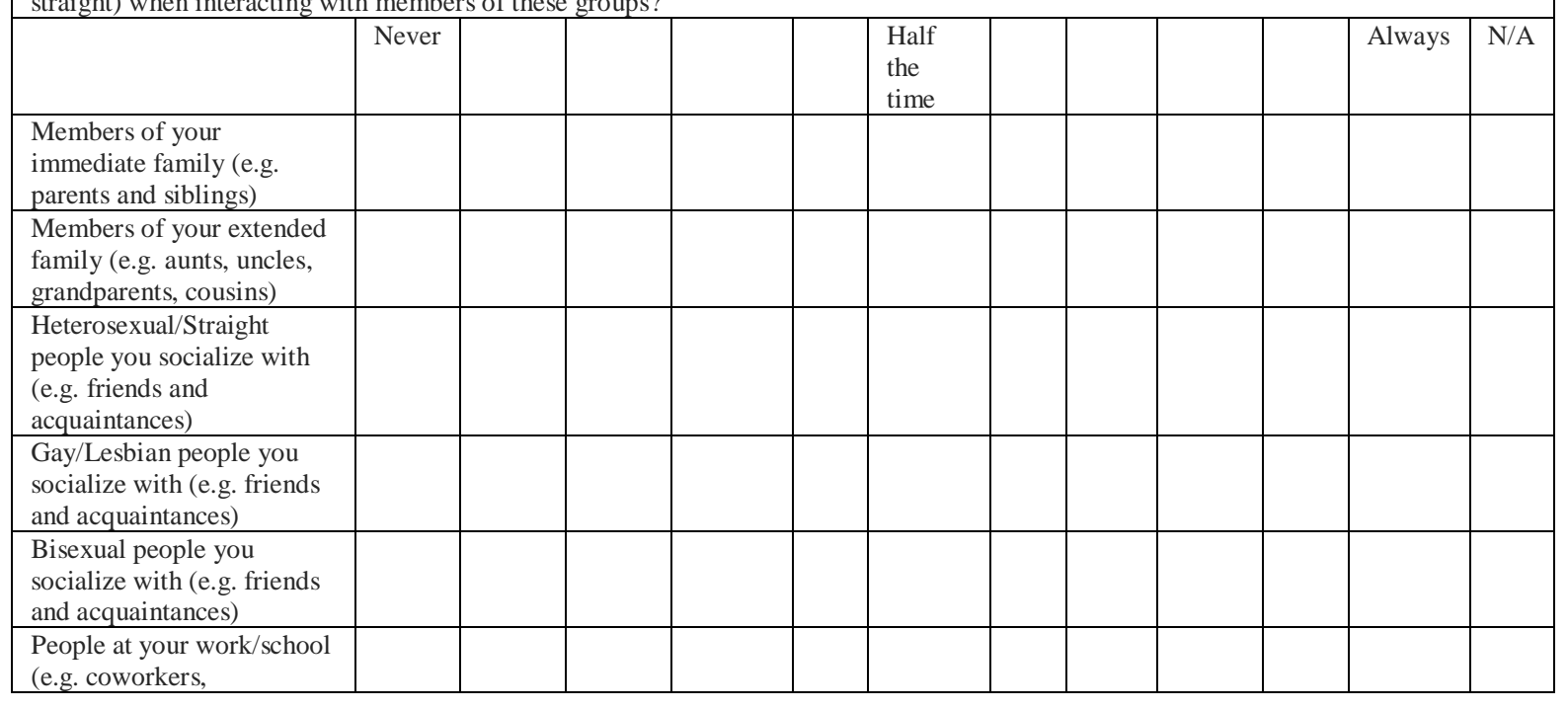




\begin{tabular}{|l|l|l|l|l|l|l|l|l|l|l|l|}
\hline $\begin{array}{l}\text { supervisors, instructors, } \\
\text { students) }\end{array}$ & & & & & & & & & & & \\
\hline $\begin{array}{l}\text { Strangers (e.g. someone } \\
\text { you have a causal } \\
\begin{array}{l}\text { conversation with in line at } \\
\text { the store) }\end{array}\end{array}$ & & & & & & & & & & & \\
\hline
\end{tabular}




\section{Appendix D}

\section{LGB-PIM, Authenticity Subscale}

\section{(Riggle et al., 2014)}

We are going to ask you a series of questions about your identity as a bisexual identified person. There are several questions and some of the questions may seem similar, but there are differences in the wording, so please try to answer all of the questions. Please answer the questions by thinking about which response category best represents your feelings about your experiences. Indicate how you really feel now, not how you think you should feel. There is no need to think too much about any one question. Answer each question according to your initial reaction and then move on to the next. Choose the response the best reflects your feelings about your bisexual identity.

\begin{tabular}{|c|c|c|c|c|c|c|c|}
\hline & $\begin{array}{l}\text { Strongly } \\
\text { Disagree }\end{array}$ & Disagree & $\begin{array}{l}\text { Somewhat } \\
\text { Disagree }\end{array}$ & $\begin{array}{l}\text { Neither Agree } \\
\text { nor Disagree }\end{array}$ & $\begin{array}{l}\text { Somewhat } \\
\text { Agree }\end{array}$ & Agree & $\begin{array}{l}\text { Strongly } \\
\text { Agree }\end{array}$ \\
\hline \multicolumn{8}{|l|}{ I am comfortable with my bisexual identity. } \\
\hline \multicolumn{8}{|l|}{$\begin{array}{l}\text { I have a sense of inner peace about my } \\
\text { bisexual identity. }\end{array}$} \\
\hline \multicolumn{8}{|l|}{$\begin{array}{l}\text { I am honest with myself about my bisexual } \\
\text { identity. }\end{array}$} \\
\hline \multicolumn{8}{|l|}{ I embrace my bisexual identity. } \\
\hline \multicolumn{8}{|l|}{$\begin{array}{l}\text { I feel I can be honest and share my bisexual } \\
\text { identity with others. }\end{array}$} \\
\hline \multicolumn{8}{|l|}{$\begin{array}{l}\text { I feel free to express my bisexual identity } \\
\text { when I interact with others. }\end{array}$} \\
\hline \multicolumn{8}{|l|}{$\begin{array}{l}\text { I am living an authentic life as a bisexual } \\
\text { person. }\end{array}$} \\
\hline \multicolumn{8}{|l|}{$\begin{array}{l}\text { I am a positive role model for other bisexual } \\
\text { people. }\end{array}$} \\
\hline \multicolumn{8}{|l|}{$\begin{array}{l}\text { It is important to me as a bisexual person to } \\
\text { speak up for myself and others. }\end{array}$} \\
\hline \multicolumn{8}{|l|}{$\begin{array}{l}\text { I inspire other people to feel safe about } \\
\text { expressing their bisexual identity. }\end{array}$} \\
\hline \multicolumn{8}{|l|}{$\begin{array}{l}\text { Being open about my bisexual identity will } \\
\text { help improve the world for others. }\end{array}$} \\
\hline \multicolumn{8}{|l|}{$\begin{array}{l}\text { I think that other bisexual people see me as a } \\
\text { role model. }\end{array}$} \\
\hline \multicolumn{8}{|l|}{ My bisexual identity helps me feel whole. } \\
\hline $\begin{array}{l}\text { My bisexual identity is a part of being a } \\
\text { positive role model for non-bisexual people. }\end{array}$ & & & & & & & \\
\hline
\end{tabular}




\section{Appendix E}

\section{Psychological Well-Being Scale}

(Ryff, 1989)

The following set of questions deals with how you feel about yourself and your life. Please remember that there are no right or wrong answers.

\begin{tabular}{|c|c|c|c|c|c|c|}
\hline $\begin{array}{l}\text { Circle the number that best describes your } \\
\text { present agreement or disagreement with each } \\
\text { statement. }\end{array}$ & $\begin{array}{l}\text { Strongly } \\
\text { Disagree }\end{array}$ & $\begin{array}{l}\text { Disagree } \\
\text { Somewhat }\end{array}$ & $\begin{array}{l}\text { Disagree } \\
\text { Slightly }\end{array}$ & $\begin{array}{l}\text { Agree } \\
\text { Slightly }\end{array}$ & $\begin{array}{c}\text { Agree } \\
\text { Somewhat }\end{array}$ & $\begin{array}{l}\text { Strongly } \\
\text { Agree }\end{array}$ \\
\hline $\begin{array}{l}\text { 1. Most people see me as loving and } \\
\text { affectionate. }\end{array}$ & 1 & 2 & 3 & 4 & 5 & 6 \\
\hline $\begin{array}{l}\text { 2. I am not afraid to voice my opinions, even } \\
\text { when they are in opposition to the opinions of } \\
\text { most people. }\end{array}$ & 1 & 2 & 3 & 4 & 5 & 6 \\
\hline $\begin{array}{l}\text { 3. In general, I feel I am in charge of the } \\
\text { situation in which I live. }\end{array}$ & 1 & 2 & 3 & 4 & 5 & 6 \\
\hline $\begin{array}{l}\text { 4. I am not interested in activities that will } \\
\text { expand my horizons. }\end{array}$ & 1 & 2 & 3 & 4 & 5 & 6 \\
\hline $\begin{array}{l}\text { 5. I live life one day at a time and don't really } \\
\text { think about the future. }\end{array}$ & 1 & 2 & 3 & 4 & 5 & 6 \\
\hline $\begin{array}{l}\text { 6. When I look at the story of my life, I am } \\
\text { pleased with how things have turned out. }\end{array}$ & 1 & 2 & 3 & 4 & 5 & 6 \\
\hline $\begin{array}{l}\text { 7. Maintaining close relationships has been } \\
\text { difficult and frustrating for me. }\end{array}$ & 1 & 2 & 3 & 4 & 5 & 6 \\
\hline $\begin{array}{l}\text { 8. My decisions are not usually influenced by } \\
\text { what everyone else is doing. }\end{array}$ & 1 & 2 & 3 & 4 & 5 & 6 \\
\hline $\begin{array}{l}\text { 9. The demands of everyday life often get me } \\
\text { down. }\end{array}$ & 1 & 2 & 3 & 4 & 5 & 6 \\
\hline $\begin{array}{l}\text { 10. I think it is important to have new } \\
\text { experiences that challenge how you think about } \\
\text { yourself and the world. }\end{array}$ & 1 & 2 & 3 & 4 & 5 & 6 \\
\hline $\begin{array}{l}\text { 11. I have a sense of direction and purpose in } \\
\text { life. }\end{array}$ & 1 & 2 & 3 & 4 & 5 & 6 \\
\hline $\begin{array}{l}\text { 12. In general, I feel confident and positive } \\
\text { about myself. }\end{array}$ & 1 & 2 & 3 & 4 & 5 & 6 \\
\hline $\begin{array}{l}\text { 13. I often feel lonely because I have few close } \\
\text { friends with whom to share my concerns. }\end{array}$ & 1 & 2 & 3 & 4 & 5 & 6 \\
\hline $\begin{array}{l}\text { 14. I tend to be influenced by people with strong } \\
\text { opinions. }\end{array}$ & 1 & 2 & 3 & 4 & 5 & 6 \\
\hline $\begin{array}{l}\text { 15. I do not fit very well with the people and the } \\
\text { community around me. }\end{array}$ & 1 & 2 & 3 & 4 & 5 & 6 \\
\hline $\begin{array}{l}\text { 16. When I think about it, I haven’t really } \\
\text { improved much as a person over the years. }\end{array}$ & 1 & 2 & 3 & 4 & 5 & 6 \\
\hline $\begin{array}{l}\text { 17. I don't have a good sense of what it is I'm } \\
\text { trying to accomplish in life. }\end{array}$ & 1 & 2 & 3 & 4 & 5 & 6 \\
\hline $\begin{array}{l}\text { 18. I feel like many of the people I know have } \\
\text { gotten more out of life than I have. }\end{array}$ & 1 & 2 & 3 & 4 & 5 & 6 \\
\hline $\begin{array}{l}\text { 19. I enjoy personal and mutual conversations } \\
\text { with family members and friends. }\end{array}$ & 1 & 2 & 3 & 4 & 5 & 6 \\
\hline
\end{tabular}




\begin{tabular}{|c|c|c|c|c|c|c|}
\hline $\begin{array}{l}\text { 20. I have confidence in my-opinions, even if } \\
\text { they are contrary to the general consensus. }\end{array}$ & 1 & 2 & 3 & 4 & 5 & 6 \\
\hline $\begin{array}{l}21 \text {. I am quite good at managing the many } \\
\text { responsibilities of my daily life. }\end{array}$ & 1 & 2 & 3 & 4 & 5 & 6 \\
\hline $\begin{array}{l}\text { 22. I have the sense that I have developed a lot } \\
\text { as a person over time. }\end{array}$ & 1 & 2 & 3 & 4 & 5 & 6 \\
\hline $\begin{array}{l}\text { 23. My daily activities often seem trivial and } \\
\text { unimportant to me. }\end{array}$ & 1 & 2 & 3 & 4 & 5 & 6 \\
\hline 24. I like most parts of my personality. & 1 & 2 & 3 & 4 & 5 & 6 \\
\hline $\begin{array}{l}\text { 25. People would describe me as a giving } \\
\text { person, willing to share my time with others. }\end{array}$ & 1 & 2 & 3 & 4 & 5 & 6 \\
\hline $\begin{array}{l}\text { 26. It's difficult for me to voice my own } \\
\text { opinions on controversial matters. }\end{array}$ & 1 & 2 & 3 & 4 & 5 & 6 \\
\hline $\begin{array}{l}\text { 27. I often feel overwhelmed by my } \\
\text { responsibilities. }\end{array}$ & 1 & 2 & 3 & 4 & 5 & 6 \\
\hline $\begin{array}{l}\text { 28. For me, life has been a continuous process of } \\
\text { learning, changing, and growth. }\end{array}$ & 1 & 2 & 3 & 4 & 5 & 6 \\
\hline $\begin{array}{l}\text { 29. I enjoy making plans for the future and } \\
\text { working to make them a reality. }\end{array}$ & 1 & 2 & 3 & 4 & 5 & 6 \\
\hline $\begin{array}{l}\text { 30. In many ways I feel disappointed about my } \\
\text { achievements in life. }\end{array}$ & 1 & 2 & 3 & 4 & 5 & 6 \\
\hline $\begin{array}{l}\text { 31. I have not experienced many warm and } \\
\text { trusting relationships with others. }\end{array}$ & 1 & 2 & 3 & 4 & 5 & 6 \\
\hline $\begin{array}{l}\text { 32. I tend to worry about what other people think } \\
\text { of me. }\end{array}$ & 1 & 2 & 3 & 4 & 5 & 6 \\
\hline $\begin{array}{l}\text { 33. I have difficulty arranging my life in a way } \\
\text { that is satisfying to me. }\end{array}$ & 1 & 2 & 3 & 4 & 5 & 6 \\
\hline $\begin{array}{l}\text { 34. I gave up trying to make big improvements } \\
\text { or changes in my life a long time ago. }\end{array}$ & 1 & 2 & 3 & 4 & 5 & 6 \\
\hline $\begin{array}{l}\text { 35. Some people wander aimlessly through life, } \\
\text { but I am not one of them. }\end{array}$ & 1 & 2 & 3 & 4 & 5 & 6 \\
\hline $\begin{array}{l}\text { 36. My attitude about myself is probably not as } \\
\text { positive as most people feel about themselves. }\end{array}$ & 1 & 2 & 3 & 4 & 5 & 6 \\
\hline $\begin{array}{l}\text { 37. I know that I can trust my friends, and they } \\
\text { know they can trust me. }\end{array}$ & 1 & 2 & 3 & 4 & 5 & 6 \\
\hline $\begin{array}{l}\text { 38. I judge myself by what I think is important, } \\
\text { not by the values of what others think is } \\
\text { important. }\end{array}$ & 1 & 2 & 3 & 4 & 5 & 6 \\
\hline $\begin{array}{l}\text { 39. I have been able to build a living } \\
\text { environment and a lifestyle for myself that is } \\
\text { much to my liking. }\end{array}$ & 1 & 2 & 3 & 4 & 5 & 6 \\
\hline $\begin{array}{l}\text { 40. I do not enjoy being in new situations that } \\
\text { require me to change my old familiar ways of } \\
\text { doing things. }\end{array}$ & 1 & 2 & 3 & 4 & 5 & 6 \\
\hline $\begin{array}{l}\text { 41. I sometimes feel as if I've done all there is to } \\
\text { do in life. }\end{array}$ & 1 & 2 & 3 & 4 & 5 & 6 \\
\hline $\begin{array}{l}\text { 42. When I compare myself to friends and } \\
\text { acquaintances, it makes me feel good about who } \\
\text { I am. }\end{array}$ & 1 & 2 & 3 & 4 & 5 & 6 \\
\hline
\end{tabular}




\section{VITA}

Jenna Marie Brownfield was born on February 24, 1990 in Columbus, Ohio. She earned her high school diploma at Gahanna Lincoln High School in 2008. She then received her Bachelor of Arts in 2012 from Rhodes College in Memphis, Tennessee, where she majored in psychology. In September 2012, she began studying for her M.A. in Counseling Psychology at the University of Denver (DU). For her clinical practicums while at DU, she trained as a therapist at the Gender Identity Center of Colorado, the Counseling and Educational Services Clinic at DU, and Community Reach Center.

After graduating from DU in June 2014, Ms. Brownfield moved to Kansas City, Missouri to pursue her Ph.D. in Counseling Psychology at the University of Missouri-Kansas City (UMKC). While at UMKC, she worked as an adjunct instructor, teaching a Master'slevel research methods course. During her doctoral career she was awarded the Student Affiliates of Seventeen Social Justice Award and the UMKC DaLee Fund Award. Her predoctoral psychology internship was at the University of Minnesota's Student Counseling Services from August 2018 thru July 2019.

Ms. Brownfield is a member of the American Psychological Association and has served as a student representative for the Div. 44, Bisexual Issues Committee. To date, she has co-authored seven articles published in refereed journals. She has nine presentations at national conferences. 